\title{
Gender Wage Gaps and Risky vs. Secure Employment: An Experimental Analysis*
}

February 27, 2018

\begin{abstract}
In addition to discrimination, market power, and human capital, gender differences in risk preferences might also contribute to observed gender wage gaps. We conduct laboratory experiments in which subjects choose between a risky (in terms of exposure to unemployment) and a secure job after being assigned in early rounds to both types of jobs. Both jobs involve the same typing task. The risky job adds the element of a known probability that the typing opportunity will not be available in any given period. Subjects were informed of the exogenous risk premium being offered for the risky job. Women were more likely than men to select the secure job, and these job choices accounted for between $40 \%$ and $77 \%$ of the gender wage gap in the experiments. A method for classifying subjects according to risk preferences is derived from the theoretical framework and further demonstrates the higher incidence of risk aversion among women.
\end{abstract}

Keywords: Occupational Choice; Gender Wage Differentials; Risk Aversion; Lab Experiment

JEL: J16; J24; J31; C91; D81

\footnotetext{
${ }^{*}$ We gratefully acknowledge helpful comments from Alberto Dávila, Martin Dufwenberg, Jungmin Lee, Alston Mackenzie, Gary Solon, and from conference and seminar participants at the University of Arizona, Georgia State University, Kent State University, and the University of Paris I/Paris School of Economics. The authors would like to thank the Paris School of Economics Research Center for having funded this research. (Grant number: Fond de Recherche PSE 2014/2015-Dossier N4)
} 


\section{Introduction}

Gender wage gaps have been the subject of an extensive number of empirical studies primarily focused on field data generated by naturally occurring labor markets. The fundamental conceptual bifurcation of the gender wage gap is between discrimination and human capital. Discrimination can arise from three distinct sources: Becker tastes and preferences, market power, and statistical discrimination. Consistent with all three theories of discrimination is a human capital explanation of gender differences in productivity endowments. Gender differences in occupational outcomes can clearly contribute to the gender wage gap. Some of this component of the wage gap can arise as a result of job segregation induced by tastes for discrimination by economic agents (Baldwin et al., 2001; Shatnawi et al., 2014). The remainder of the occupational outcome gap can arise from gender differences in preferences over various job attributes that are associated with compensating differentials.

One potentially salient job attribute is the risk of involuntary unemployment. Earlier research has revealed that rates of involuntary job loss are significantly higher among male employees than among female counterparts (Blau and Kahn (1981)). Wilkins and Wooden (2013) argue that this phenomenon arises from the systematic differences in the types of occupations into which men and women choose. Depending on the distribution of risk attitudes pertaining to spells of unemployment, there will be some compensating differential that arises in the labor market. The degree to which men and women differentially sort themselves into risky vs. secure jobs has implications for the gender wage gap. A recent study examined this issue in the context of public vs. private sector employment and the gender wage gap (Jung, 2017). Unfortunately, in the naturally occurring labor market there are a host of factors that can be confounded with risk aversion given the multidimensional nature of the job package, e.g. family friendly policies, commuting distance, etc.

Numerous earlier studies using field data with the decomposition method suggest that there are unexplained wage gaps, i.e. Oaxaca (1973); Bayard et al. (2003); Hotchkiss and Pitts (2007), etc. On the other hand, a large body of experimental research provides evidence that women are more risk averse than men in a variety of contexts such as valuation of gambles and /or choices among gambles (Levin et al. (1988); Hartog et al. (2002))) risky 
decisions within contextual environments such as investment and insurance (Gysler et al. (2002); Schubert (1999)). However, there is not an abundance of evidence that shows the direct link between gender differentials in risk attitudes and wage gaps.

To the best of our knowledge, this study is the first to use the laboratory to identify the potential role of risk aversion in explaining gender wage gaps in a setting in which we can abstract from a myriad of factors normally present in field labor markets, including labor market discrimination and competition aversion. Experiments are conducted in which subjects are given the opportunity to choose between two typings tasks differentiated only by the prospect of exogenous spells of unemployment. The risky task is accompanied by a wage premium. Gender gaps that arise in our experimental design can only come from gender differences in typing performance and job choices. Women were more likely than men to select the secure job, and wage decomposition analysis reveals that these job choices accounted for between $40 \%$ and $77 \%$ of the gender wage gap in the experiments.

Of course the laboratory experiments described in this paper are not intended to reflect population parameters in the naturally occurring labor market. Rather, the idea behind the typing task and the decomposition is to better motivate the relevance of the experiment to the naturally occurring labor market. Toward that end, we implement a design that allows for possible gender differences in the wage determining characteristics as well as gender differences in job choices where there is an element of earnings risk and a wage premium for assuming that risk.

\section{Literature}

Economists' recognition of the association between wages and job characteristics has a long history. Adam Smith argued in Wealth of Nations that wages could be determined by different characteristics of jobs such as risk (Smith, 1776). Since the time of Adam Smith, the theory of compensating wage differentials has been widely studied. Murphy et al. (1987) and Moore (1995) show that job sectors with higher unemployment and greater risk tend to have higher wages. Hence, job-sorting decisions may well vary with individuals' attitudes toward risk. More recent work such as Hartog et al. (2003) also shows that jobs 
with greater risk command higher wages, contributing to the theory of compensating wage differentials. Workers who are more willing to accept a certain number of dollars for a given increase in risk are more likely to choose to work in riskier jobs than those who are less inclined to make a trade-off between wages and risk. While job-sector choice is sensitive to differences in risk attitudes, it is a priori also strongly correlated with education decisions.

Depending on the individual's degree of risk aversion, risk averse workers place more value on employment stability while others who are less risk averse may prefer trading off stability against the higher wage (risk premium) in the private sector. This argument has been widely studied for decades. For example, Bellante and Link (1981) used the index of innate risk aversion measure (proxies such as insurance investment, seat belt use, etc.) and showed that the probability of choosing to work in the public sector increases as the degree of risk aversion increases. A recent study using the large scale German Socio Economic Panel found that risk averse workers tend to sort into public sector employment while risk taking is rewarded with higher wages in the private sector (Pfeifer, 2011). With the use of revealed risk preferences data, Buurman et al. (2012) validate the argument that public workers are significantly less likely to choose the risky option (lotteries).

Ekelund et al. (2005) use a psychometric variable measuring harm avoidance as an indicator of risk attitudes. They find that agents with a higher harm-avoidance score (i.e. less risk averse) are less likely to become self-employed, which is considered riskier than being employed as a wage earner. In an experimental study, Dohmen et al. (2005) show that measures of subjective risk attitudes, such as self-reported risk aversion and lottery questions, provide a valid predictor of actual risk behavior. Dohmen and Falk (2011) build upon these results and use self-reported risk aversion in the German Socioeconomic Panel to examine whether risk preferences explain how individuals are sorted into occupations with different earnings variation. Pissarides (1974) presents a theoretical model explaining that risk-averse workers have lower reservation wages. Cox and Oaxaca (1989) suggest a negative relationship between the degree of risk aversion and the level of reservation wages and Cox and Oaxaca (1992) and Cox and Oaxaca (1996) re-validate the argument by experimental evidence on individual search behavior. This relationship is demonstrated empirically by Pannenberg (2007). Similarly, Goerke and Pannenberg (2012) show that 
there is a negative relationship between risk aversion and union membership.

Given that job sorting matters in terms of the position actually held in the labor market, there is good reason to wonder whether the job-sorting decision interacts with the gender disparity observed in the labor market. Although the gender bias in education has been reduced and the education gap between men and women has narrowed in recent decades (Arnot et al., 1999), there is still concern over the considerable wage gap and other kinds of gender-based discrimination in the labor market. In a move to explain these findings, Eckel and Grossman (2008), Croson and Gneezy (2009), Bertrand (2011), and Filippin and Crosetto (2016) argue that women may be more risk averse and less competitive than men. More interestingly for our question, Gneezy et al. (2003), Niederle and Vesterlund (2007) and Croson and Gneezy (2009) all suggest that differences in risk attitudes might partly explain the gender gap in labor-market outcomes. Similarly, Barsky et al. (1997), Dohmen and Falk (2011) and Bonin et al. (2007) show that job-sector selection and wages are correlated with risk attitudes.

In their seminal paper Niederle and Vesterlund (2007) seek to determine the relative importance of several factors - pure preference, over confidence, risk aversion, and feedback aversion in accounting for gender differences in preferences for competition. ${ }^{1}$ The authors employ the vehicle of tournament entry to explore gender differences in competitiveness. Subjects are asked to choose between piece-rate and a tournament to determine the form of compensation for their prior performance in a noncompetitive task. In their findings, the gap in selection into a competitive environment is driven by men being more overconfident and by gender differences in preferences for performing in competition, but risk only plays a negligible role. In contrast, Dohmen and Falk (2011) find that part of gender differences can be attributed to differences in productivity and risk preferences. In a field experiment on aged 9-12 in Columbia and Sweden, it is observed that boys are more likely to prefer competition in general and more risk taking (Cardenas et al. (2012)).

In our setting, subjects experience payment schemes corresponding to both a risky

\footnotetext{
${ }^{1}$ There is an extensive number of studies focusing on gender differences in competitiveness and confidence, as important sources of the gender wage gap (Niederle and Vesterlund (2007); Croson and Gneezy (2009); Niederle and Vesterlund (2011); Kamas and Preston (2012); Buser et al. (2014)). However, unlike these studies, our paper focuses on gender differences in risk preference which will partly explain the wage gap by an experimental setting which does not contain any trace of competition.
} 
(in terms of exposure to unemployment) and a secure job, and then in the final stage subjects choose between the risky and the secure job. Therefore, our setting shares some similarities with the setting in Niederle and Vesterlund (2007) in that subjects experience both payment schemes and are asked to choose which payment scheme they prefer in the following round. However, because our research objective is different, our experimental design differs significantly in a couple of important respects from that found in Niederle and Vesterlund (2007). There is no element of competition in our design so that the focus can be entirely on gender differences in financially risky versus secure job environments and the implications of these choices for generating gender wage gaps apart from any productivity based factors.

\section{Conceptual Framework}

\section{III.1 Secure Job}

Let compensation for the secure job follow a simple piece rate scheme: $W_{s}=\gamma_{s} P$, where $W_{s}$ is the earnings from performance of the task, $P$ is a discrete output measure of performance (to be defined below), and $\gamma_{s}$ is the marginal return to performance for the secure job. For any given individual, productivity/performance is a random variable: $P_{i}=\psi_{i}+\varepsilon_{i}$, where $\psi_{i}=E\left(P_{i}\right)>0$ (mean productivity) and $\varepsilon_{i} \sim i . i . d\left(0, \sigma_{i}^{2}\right)$. Accordingly, $\operatorname{Var}\left(P_{i}\right)=\sigma_{i}^{2}$.

For an individual employed in the secure job, wages are determined according to $W_{s i}=\gamma_{s} P_{i}$. The mean and variance from the individual's wage distribution are readily obtained as

$$
\begin{gathered}
E\left(W_{s i}\right)=\gamma_{s} \psi_{i} \\
\operatorname{Var}\left(W_{s i}\right)=\left(\gamma_{s}\right)^{2} \sigma_{i}^{2} .
\end{gathered}
$$

\section{III.2 Risky Job}

Conditional on productivity, let compensation in the risky job $\left(W_{r}\right)$ be determined according to 


\begin{tabular}{l|l}
$W_{r}$ & $\operatorname{Prob}\left(W_{r}=k\right)$ \\
\hline$w_{u}$ & $\phi$ \\
$w_{r}$ & $1-\phi$
\end{tabular}

where $\phi$ is the probability of drawing unemployment, $w_{u}$ is unemployment compensation, $w_{r}=\gamma_{r} P$ is the earnings from employment in the risky job, and $\gamma_{r}$ is the marginal return to performance for the risky job.

It can be shown that the mean and variance of the conditional wage distribution are given by $E\left(W_{r} \mid P\right)=\phi w_{u}+(1-\phi) \gamma_{r} P$ and $\operatorname{Var}\left(W_{r} \mid P\right)=(\phi)(1-\phi)\left(\gamma_{r} P-w_{u}\right)^{2}$. The law of iterated expectations and the law of total variance are used to obtain the unconditional moments of the wage distribution for a given individual:

$E\left(W_{r i}\right)=\phi w_{u}+(1-\phi) \gamma_{r} \psi_{i}$ and $\operatorname{Var}\left(W_{r i}\right)=(\phi)(1-\phi)\left(\gamma_{r} \psi_{i}-w_{u}\right)^{2}+(1-\phi)\left(\gamma_{r}\right)^{2} \sigma_{i}^{2}$.

\section{III.3 Risk Premium}

For a given marginal return to performance on the secure job $\left(\gamma_{s}\right)$, one can readily solve for the compensating risk premium for a risk neutral agent with productivity $\psi_{i}$ :

$$
\begin{gathered}
E\left(W_{r i}\right)=E\left(W_{s i}\right) \\
\Rightarrow \quad \phi w_{u}+(1-\phi) \gamma_{r} \psi_{i}=\gamma_{s} \psi_{i} \\
\Rightarrow \quad \gamma_{r i}-\gamma_{s}=\left(\frac{\phi}{1-\phi}\right)\left(\gamma_{s}-\frac{w_{u}}{\psi_{i}}\right)>0,
\end{gathered}
$$

where $\gamma_{r i}-\gamma_{s}$ is the compensating risk premium that would just render the risk neutral agent indifferent between the secure job and the risky job.

Note that $\gamma_{s}-\frac{w_{u}}{\psi_{i}}>0 \Rightarrow w_{u}<\gamma_{s} \psi_{i}$, i.e., to ensure a positive risk premium, the unemployment compensation must be less than the expected marginal revenue product (return) on the secure job. Also, note that the compensating risk premium $\gamma_{r i}-\gamma_{s}$ is 
increasing in $\phi$ (unemployment risk) and $\psi_{i}$ (skill), and is decreasing in $w_{u}$ (unemployment compensation).

\section{Experimental Design}

Subjects were recruited from the University of Paris I. ${ }^{2}$ At the conclusion of the experiment, a questionnaire was administered to the subjects. This was done to not only obtain basic demographic information, but also to measure risk attitudes elicited on the basis of hypothetical Holt-Laury lottery choices (Holt and Laury (2002)) provided to the subjects.

\section{IV.1 Treatments}

In our experiments earnings from the secure job depend only on performance. There is no risk of unemployment. By contrast earnings from the risky job depend on performance and chance (risk of unemployment). Furthermore, receipt of the unemployment benefit $w_{u}$ occurs with probability $\phi$, and the receipt of earnings $w_{r i}=\gamma_{r} P_{i}$ occurs with probability $1-\phi$. Subjects were fully informed about the payoffs for performance and the unemployment probability for the risky job.

Each subject participates in three treatments:

- Treatment 1: half of the subjects are randomly assigned to the risky job and the other half are assigned to the secure job.

- Treatment 2: the subjects assigned to the risky (secure) job in Treatment 1 are assigned to the secure (risky) job in treatment 2 .

- Treatment 3: the subjects choose between the risky job and the secure job.

We conducted two sets of experiments in which Treatments 1 - 3 were run with two different risk premiums $\left(\gamma_{r}-\gamma_{s}\right)$. There was no overlap of subjects between the two risk premium experiments.

\footnotetext{
${ }^{2}$ Laboratoire d'Economie Expérimentale de Paris
} 


\section{IV.2 Effort Tasks and Compensation}

Subjects earn income from working by typing randomly generated blocks of 5 letters. Compensation is derived from a subject's performance measured by $P_{i}$ which corresponds to the number of correctly typed blocks. In each period there are 40 random, 5 letter blocks, so $0 \leq P_{i} \leq 40$. There are 10 periods in each experimental trial. Subjects are given 90 seconds each period to type.

All subjects were confronted with the same sequence of letter blocks over the 10 periods within a given treatment (Treatments 1 - 3) but the sequences were different across the treatments. After each period, each subject's screen displays the number of words that they correctly typed and the earnings of that period based on the job type.

At the end of each experimental session, a period was drawn randomly from each of Treatments 1 - 3 separately for each subject, and each subject was then compensated on the basis of their performances in the 3 randomly selected periods.

\section{IV.3 Experimental Design Parameters}

It is important to set parameter design values such that sufficient numbers of subjects will be attracted to the risky job and to the secure job. Naturally, we do not know the risk attitudes of each subject ex ante, nor do we know each subject's productivity distribution ex ante. On the basis of simple calculations that assumed average subject productivity ranging from $33 \%$ to $75 \%$ accuracy coupled with different trial values of the returns to productivity, we were able to adopt reasonable values of the experimental design parameters.

For our design we fixed the values of $w_{u}, \phi$, and $\gamma_{r}$ and varied $\gamma_{s}$. The experimental design values were set according to $w_{u}=€ 1, \phi=0.3, \gamma_{r}=€ 0.2, \gamma_{s}=€ 0.13$ or $€ 0.14$. Accordingly, the two risk premium experiments corresponded to $\gamma_{r}-\gamma_{s}=€ 0.07$ and $€ 0.06$. The inclusion of a risk premium treatment affords us the opportunity to gain additional insights from the responses of subjects to changes in the incentives to assume risk. In particular we seek to learn whether the premium treatment is gender neutral in its effects on risky job choice and gender wage gaps. 


\section{Empirical Analysis and Results}

\section{V.1 Decomposition Analysis}

Our objective is to be able to measure the effect of gender differences in job choice on any gender wage gaps that arise within our experimental setting. This is accomplished through the decomposition methods developed in the Technical Appendix. For a given risk premium within the endogenous choice treatment (Treatment 3), the gender wage gap decomposition may be expressed as

$$
\begin{aligned}
w_{m}-w_{f} & =\underbrace{\gamma_{r}\left(P_{r}^{m}-P_{r}^{f}\right) \theta_{r}^{f}+\gamma_{s}\left(P_{s}^{m}-P_{s}^{f}\right)\left(1-\theta_{r}^{f}\right)}_{\text {productivity }} \\
& +\underbrace{\left(\gamma_{r} P_{r}^{m}-\gamma_{s} P_{s}^{m}\right)\left(\theta_{r}^{m}-\theta_{r}^{f}\right)}_{\text {job choice }},
\end{aligned}
$$

or alternatively as

$$
\begin{aligned}
w_{m}-w_{f} & =\underbrace{\gamma_{r}\left(P_{r}^{m}-P_{r}^{f}\right) \theta_{r}^{m}+\gamma_{s}\left(P_{s}^{m}-P_{s}^{f}\right)\left(1-\theta_{r}^{m}\right)}_{\text {productivity }} \\
& +\underbrace{\left(\gamma_{r} P_{r}^{f}-\gamma_{s} P_{s}^{f}\right)\left(\theta_{r}^{m}-\theta_{r}^{f}\right)}_{\text {job choice }},
\end{aligned}
$$

where $\theta_{r}^{j}$ is the sample proportion of the wage observations in the endogenous choice treatment associated with the risky job choices. These alternative decompositions arise from weighting the gender differences in productivity, $\left(P_{r}^{m}-P_{r}^{f}\right)$ and $\left(P_{s}^{m}-P_{s}^{f}\right)$ by either $\theta_{r}^{f}$ or $\theta_{r}^{m}$.

\section{V.2 Identification of Individual Risk Attitudes}

Relevant to our analysis of gender wage gaps and gender differences in risk preferences is a property of our conceptual framework that leads directly to a classification of subjects according to what one can interpret as risk preferences. This risk assignment classification can be viewed as an alternative to the HL measure of risk preferences. While it is not 
possible for our framework to precisely identify risk attitudes for every subject, it is possible to identify subsets of individuals who are either risk averse or risk loving. The key to this identification is the presence of unemployment compensation $w_{u}$ which allows one to compare each subject's job choice with the difference between their predicted risk neutral premium and the experimental risk premium.

Upon substitution of an estimate for $\psi_{i}$ in eq.(4) for each subject, one can estimate the compensating risk premium if the subject were risk neutral:

$$
\left(\widehat{\gamma_{r}-\gamma_{s}}\right)_{i}=\left(\frac{\phi}{1-\phi}\right)\left(\gamma_{s}-\frac{w_{u}}{\hat{\psi}_{i}}\right)
$$

where $\hat{\psi}_{i}$ is the average number of correctly typed blocks over the last observed five periods in the assigned treatment.

Let $R_{i}=1\left(J_{i}=r\right)$ be an indicator for choosing the risky job. A subject's risk attitudes are identified under the following conditions:

$$
\begin{aligned}
& \left(\widehat{\gamma_{r}-\gamma_{s}}\right)_{i}<\gamma_{r}-\gamma_{s} \text { and } R_{i}=0 \Rightarrow \text { risk averse } \\
& \left(\widehat{\gamma_{r}-\gamma_{s}}\right)_{i}>\gamma_{r}-\gamma_{s} \text { and } R_{i}=1 \Rightarrow \text { risk loving. }
\end{aligned}
$$

Condition (8) states that if a subject's estimated risk premium under risk neutrality is less than the experimental risk premium, and the subject chooses the secure job, that subject is classified as risk averse. Similarly condition (9) states that if a subject's estimated risk premium under risk neutrality exceeds the experimental risk premium, and the subject chooses the risky job, that subject is classified as risk loving.

Note that the reverse of conditions (8) and (9) is not true, i.e.

$$
\begin{aligned}
& \text { risk averse } \nRightarrow\left(\widehat{\gamma_{r}-\gamma_{s}}\right)_{i}<\gamma_{r}-\gamma_{s} \text { and } R_{i}=0 \\
& \text { risk loving } \nRightarrow\left(\widehat{\gamma_{r}-\gamma_{s}}\right)_{i}>\gamma_{r}-\gamma_{s} \text { and } R_{i}=1
\end{aligned}
$$

The compliment of the sets of observations corresponding to conditions (8) and (9) is given 
by

$$
\begin{aligned}
& \left(\widehat{\gamma_{r}-\gamma_{s}}\right)_{i} \leq \gamma_{r}-\gamma_{s} \text { and } R_{i}=1 \Rightarrow \text { risk attitude not identified } \\
& \left(\widehat{\gamma_{r}-\gamma_{s}}\right)_{i} \geq \gamma_{r}-\gamma_{s} \text { and } R_{i}=0 \Rightarrow \text { risk attitude not identified. }
\end{aligned}
$$

Satisfaction of condition (10) or (11) is consistent with risk aversion, risk neutrality, or risk loving.

\section{V.3 Empirical findings}

There was a total of 192 subjects who participated in the experiments: 97 in the $€ 0.07$ risk premium experiment ( 54 men and 43 women), and 95 subjects who participated in the $€ 0.06$ risk premium experiment (49 men and 46 women).

Table 1 presents selected descriptive statistics separated out as Personal (not associated with behavior during the experiment) and Experimental (behavior in the experiment). Subjects averaged 23 years of age with no gender difference in average age. We find no statistical difference in Holt and Laury Risk Aversion between genders. On average the typing performance of men exceeded that of women by a statistically significant margin of 1.39 correctly typed words. Unemployment realizations were the same for men and women at 0.31 which is very close to the experimental design value of 0.30 . Finally, the proportion of men who chose the risky job exceeded that of the women by a statistically significant 0.15 .

Tables 2 - 5 report the productivity and wage outcomes for the $€ 0.07$ and $€ 0.06$ risk premium experiments. For both risk premium experiments, the reported wage outcomes within jobs are by design proportional to the corresponding productivity outcomes. In the $€ 0.07$ risk premium experiments (Table 2), the typing performance of men was virtually identical between the assigned treatments and the choice treatment (23.21 words and 23.31 words, respectively). Typing performance for women was also much the same between the assigned treatments and the choice treatment (22.07 words and 21.67 words, respectively). Despite the similar patterns for both men and women when comparing performances between the assigned and choice treatments, women averaged fewer correctly typed words 
than men in both the assigned treatments and the choice treatment. These differences were statistically significant and generated statistically significant gender wage gaps (Table 3). Similar patterns appear in the $€ 0.06$ risk premium experiments (Table 4). Typing performance was virtually the same between the assigned treatments and the choice treatments for both men and women. Again, despite the similar patterns, women averaged fewer correctly typed words than men in both the assigned and the choice treatments. As Table 5 shows, these differences in typing performance yielded statistically significant gender wage gaps in both the assigned and the choice treatments.

Of particular interest are the patterns associated with risky versus secure job choices in the choice treatment. In the $€ 0.07$ risk premium experiments (Table 2) the typing performance of men was virtually identical between those who chose the risky job and those who selected the secure job. The average wage for men was higher for those who selected the risky job (Table 3). Among women, those who chose the secure job were significantly more productive than those who chose the secure job (23.00 vs 21.29$)$ yet they still earned less than the women who chose the risky job. However, the average performance of the women who selected the risky job was significantly less than that of the men who selected the risky job. On the other hand, women who selected the secure job performed virtually the same as the men who selected the secure job.

When we examine job choice in the $€ 0.06$ risk premium experiments, we find that the men who selected the risky job were significantly less productive than those who selected the secure job (Table 4) but still earned a higher average wage than the men who chose the secure job (Table 5). By contrast, women who selected the risky job were significantly more productive than those who selected the secure job and also earned a higher average wage. While the women who chose the secure job were less productive than the men who chose the secure job, women in the risky job were more productive than the men in the risky job.

A closer examination of our findings reveals that the gender wage gap in the secure job in the job choice treatment vanishes because the gender gap in typing performance dropped from 4.23 correctly typed words in the $€ 0.06$ risk premium experiment to 0.42 in the $€ 0.07$ risk premium experiment. According to the theoretical framework shown above, 
one might expect that the increased risk premium should induce more productive workers to select the risky job. Although we might expect less productive workers to end up in the secure job for both men and women in response to a higher risk premium, this would not in and of itself yield any predictions about the gender wage gap in the secure job. Consistent with theoretical expectations, the performance of males choosing the risky job relative to those choosing the secure job was higher in the RP 0.07 treatment. However, this was not the case for women. For women, the ratio of risky job to secure job productivity was less in the RP 0.07 treatment.

Table 6 is an overview of gender differences in job choice. We report two measures of risky job choice: the proportion of individuals within each gender group who selected the risky job $(n)$; and the proportion of wage payments within each gender group arising from the selected risky job $\left(\theta_{r}\right)$. For both measures in both risk premium experiments, the risk proportions for men are higher. ${ }^{3}$ The higher risk premium attracts higher proportions of both men and women to the risky job, but the increased attraction of the risky job is proportionately greater for women. Increasing the risk premium monotonically attracts more subjects to choose the risky job. In the limit we would almost certainly observe no gender difference in job choice as the financial rewards would induce even the most risk averse subjects to choose the risky job. One would expect women to be more responsive to risk premium changes because women are at a lower saturation point with respect to risky job choice. Consequently, the gender risk proportion gaps associated with the choice of the risky job diminish when the risk premium is higher. So for example the gender difference in the proportion of individuals choosing the risky job when the risk premium is $€ 0.06$ is 19 percentage points. This gap falls to 11 percentage points with the higher risk premium of

\footnotetext{
${ }^{3}$ Among participants in the $€ 0.07$ risk premium experiments, $76 \%$ of the men and $65 \%$ of the women chose the risky job in the choice treatments. In the $€ 0.06$ risk premium experiments, $73 \%$ of the men and $54 \%$ of the women chose the risky job in the choice treatments. Therefore, in both experiments, a higher proportion of men chose the risky job. Our alternative measure of risky choice is $\theta_{r}$, the proportion of observations corresponding to the risky job. We only consider observations for which participants are employed, i.e. performing the typing task. In the risky job treatment, participants encountered a $30 \%$ probability of not being offered the opportunity to perform the typing task (i.e. unemployed) in each period. This yields an expected 7 observations for each individual in the risky jobs. If men are less risk averse than women in the choice treatment, on average we would expect that $\theta_{r m}>\theta_{r f}$ ), i.e., a larger share of the observations for men would come from the risky job. Using the $\theta_{r}$ measure, we find that a higher share of male observations are coming from the risky job in comparison to that of female observations $(0.70$ vs. 0.54 in the $€ 0.07$ risk premium experiments, and 0.66 vs. 0.45 int $€ 0.06$ risk premium experiment).
} 
$€ 0.07$. In a similar vein Petrie and Segal (2017) find that the gender gap in the propensity to enter a tournament diminishes with the magnitude of the tournament premium.

We find that the gender gaps in choosing the risky job are statistically significant for the lower risk premium experiment and marginally insignificant for the wage payment proportions in the higher risk premium experiment. With one exception, the hypothesis that the risky job proportions are lower for men can be rejected in favor of higher risky job proportions for men. The exception for this one-tailed test occurs in the case of the proportion of individuals in the higher risk premium experiment. Failure to reject the null is marginal in this case.

Table 7 reports the results from our risk attitude classifications according to conditions (8), (9), (10), and (11). As it turned out, the predicted risk premium under risk neutrality for every subject was less than the experimental risk premium. This means that conditions (9) and (11) were never satisfied in the data. Consequently, no risk loving subjects were identified, and all of the subjects whose risk attitudes were not identified satisfied condition (10). The proportion of subjects who were identified as risk averse was higher for women in both risk premium experiments. Predictably, the proportions for both genders were lower in the higher risk premium experiment. This is consistent with the findings reported in Table 6. Furthermore, proportionately fewer women were identified as risk averse in the higher risk premium experiment. This is is also consistent with the findings reported in Table $6 .^{4}$

Wage decompositions generated by subject job choices are reported in Table 8 . Wages on average were higher for men in both risk premium treatments. The gender wage gap in the $€ 0.07$ risk premium experiment was $€ 0.50$. Depending on which risky job wage payment fraction ( $\theta_{r}^{f}$ for women or $\theta_{r}^{m}$ for men) is used to weight gender differences in performance, the propensity of women to select the secure job accounts for $€ 0.26$ (52\%) or $€ 0.20$ (40\%) of the wage gap. For the $€ 0.06$ risk premium treatment the gender wage gap was slightly lower at $€ 0.47$. Again depending on which risky job wage payment fraction is used to weight gender differences in performance, the propensity of women to select

\footnotetext{
${ }^{4}$ We also examined how well the observed choices could be rationalized by a Constant Absolute Risk Aversion Utility function. The findings are consistent with women being less risk averse than men. The interested reader is referred to the Technical Appendix for details.
} 
the secure job can account for $€ 0.20$ (43\%) or as much as $€ 0.36(77 \%)$ of the wage gap. When the two sets of risk premium experiments are combined using the experiment sample weights for men $\left(\Omega_{m}=0.537\right)$ to weight gender differences in productivity within jobs, the overall wage gap averaged to $€ 0.48$. Under our two alternative overall wage decompositions, job choice accounts for an average of $€ 0.23$ (48\%) or $€ 0.27(56 \%)$ of the gender wage gap. Rounding error and the contribution of differences in the experiment sample weights are minor and exactly offsetting. ${ }^{5}$

To discover what additional factors beyond gender can explain subject job choices, we estimate a probit model of risky job choice. Table 9 reports the results of this exercise. When conditioning on other factors, being a women exhibits a consistently negative effect on the probability of choosing the risky job. This negative effect is statistically significant overall and for the lower risk premium treatment but not the higher risk premium treatment. Age of the subject and the subject's average typing performance over the most recent five periods in the assigned treatment are never statistically significant. Nevertheless, the productivity effect is consistently negative. This is consistent with the theoretical reasoning that suggests that the higher one's productivity, the higher risk premium would need to be to induce a risk neutral agent to choose the risky job.

Interestingly, the Holt-Laury risk aversion measure consistently exhibits a negative effect on the probability of selecting the risky job though it is only statistically significant overall but not in the individual risk premium experiments. Table 9 tells us that when controlling for the Holt and Laury type risk aversion, gender differences still remain in terms of the choice of the risky job. Our experimental design only differentiates between secure jobs and risky jobs with respect to the level of unemployment risk. Therefore, in terms of choosing between the secure and the risky jobs, the only factor (besides the subject's productivity) which determines the choice must be risk attitudes. It is, therefore, reasonable to obtain significantly negative coefficients for HL risk aversion on choosing risky jobs. However, still we observe a significant gender difference between males and females. We believe that this gender gap might capture a different dimension of risk preference.

\footnotetext{
${ }^{5}$ Using the experiment sample weights for women $\left(\Omega_{f}=0.463\right)$ yielded very nearly identical decompositions.
} 
Recent studies suggest that the gender differences in risk taking might be very different depending on different methods of eliciting risk preference (for example, see Filippin (2016)), and risk can have various dimensions (see Dohmen and Falk (2011)). As shown in Table 1, HL risk aversion does not seem to statistically differ between genders. This does not necessarily mean, though, that the HL measure is not working well. The results in Table 9 clearly show that the HL risk aversion retains some explanatory power. Because we observe that women choose risky jobs less often in comparison to men, we would certainly reject the proposition that there is no gender difference in risk attitudes. We can conclude that the gender gap in risk attitudes exist in our sample, but it is not well captured by the HL risk aversion measure. Consequently, that there is no statistically significant gender difference in the HL measure despite the clear gender difference in job choice suggests the limitations of this measure for predicting gender differences in risky job choices.

The strongest results with respect to risky job choice stem from the effects of a subject's actual experience of unemployment in the assigned treatment. The more often a subject actually experienced unemployment in the assigned treatments, the less likely they were to choose the risky job. This effect is statistically significant overall and in the separate risk premium experiments. Statistical significance is exhibited despite the fact that subjects are fully informed about the probability of drawing an unemployment spell. ${ }^{6}$ A possible order effect of which type of jobs the subject first experiences in the first two assigned treatments in terms of choosing risky jobs in the choice treatment, does not seem to exist. Coefficients for the dummy variable of experiencing the risky job type just before the choice decision are never significant. Although the higher risk premium experiment drew more subjects to the risky job, the positive effect of the higher risk premium is not statistically significant.

We explore the determinants of typing performance beyond gender in a random effects model of performance differentiated by risk premium and risky vs. secure employment. Performance is measured each period as the number of correctly typed 5-letter blocks. In the risky job, observations are omitted when the subject draws an unemployment spell. ${ }^{7}$

\footnotetext{
${ }^{6}$ One might conjecture that men are more optimistic relative to women about the actual realizations of unemployment they would experience. We interacted gender with unemployment history and found no statistically significant difference between men and women in the negative effects of prior unemployment on endogenous job choice in round 3.

${ }^{7}$ When a spell of unemployment is drawn, performance is of course censored. Because unemployment
} 
The results are reported in Table 10. After conditioning on the Holt-Laury risk measure, age, and period, the effects of being female on typing performance is negative in 6 out 8 cases. However, this effect is statistically significant only among those who selected the risky job in the higher risk premium experiment. The effect of being female on typing performance is positive but not statistically significant for the secure job when chosen in the higher risk premium experiment and for the risky job chosen in the lower risk premium treatment.

The Holt-Laury risk measure is statistically significant in three cases. All three of these are in the higher risk premium experiment and show a negative association with performance for the assigned risky job, the assigned secure job, and the selected risky job. Age of the subject uniformly exhibits a negative effect on performance but is statistically significant only in the higher risk premium treatments. Perhaps most interesting are the period effects. In both risk premium experiments, the variable 'Period' had a positive and statistically significant effect on performance only in the assigned treatments. This is consistent with subjects learning the typing task during the assigned treatment with no further learning taking place on average by the time the subjects are asked to choose between the risky and the secure job.

We also examine whether or not the gender effects and the effects of the Holt-Laury risk measure are significantly different between the risky job and the secure job, i.e. $\beta_{r}^{F}-\beta_{s}^{F}$, and $\beta_{r}^{R}-\beta_{s}^{R}$. These differences are examined separately but not jointly and are statistically significant only for job choice in the higher risk premium experiment. Relative to men, women who chose the risky job in the higher risk premium experiment did not perform as well as those who selected the secure job. Typing performance is negatively associated with the Holt-Laury risk measure for those who chose the risky job relative to those who selected the secure job.

spells are exogenous, there is no censoring bias arising from random effects estimation. Consequently, random effects tobit is not the appropriate estimator in this case. 


\section{Discussion}

When comparing subject behavior in the higher risk premium experiment (0.07) against behavior in the lower risk premium experiment (0.06) we are relying on a cross-subject design since subjects experienced only one of the two risk premiums. Since the subjects are drawn from the same subject pool, we can think of differences in behavior between the two experiments as risk premium treatment effects. Unconditionally, the higher risk premium increases the propensity to select the risky job. When conditioning on other factors, this effect persists but loses precision in a probit model of job choice.

One might speculate about whether or not an additional incentive to choose the risky job is utility gained from the leisure time associated with drawing a spell of unemployment. Our results strongly reveal the negative impact of unemployment experienced during the assigned treatment phase on the subsequent probability of choosing the risky job. This is indicative of an aversion to income loss occasioned by unemployment as opposed to any positive utility of leisure.

In seeking to uncover the independent effects of ex ante productivity on job choice, we use an average of the five most recently observed typing performances in the assigned job phase. Our analysis of the data strongly supports the notion that this measure is a reasonable proxy for subjects' beliefs about their expected typing abilities. In the assigned job treatment rounds of the experiment, learning is evidenced by the positive and statistically significant effect of Period on (log) typing performance. Whereas in the subsequent job choice treatment rounds, there is a complete lack of statistical significance of Period on typing performance. Thus, in the assigned job treatments there is a positive trend in typing performance but in the job choice treatment there is no trend in typing performance. We therefore conclude that learning has pretty much terminated by the time subjects are exposed to the job choice treatment.

Although our experimental design was not intended to examine gender differences in overconfidence, the possible existence of male overconfidence in abilities has implications for our findings. As shown above, the theoretical model developed in the paper (eq.(4)) shows cet.par. that the compensating risk premium is increasing in skill level. So for any 
given risk premium, an increase in skill level would presumably reduce the probability that one would select the risky job. In other words, the higher one's skill level the higher the risk premium would have to be in order for one to put their skills at risk. Although Table 9 shows that productivity is not statistically significant in explaining risky job choice, it is consistently negative. Other things equal, one would think that if men are relatively more overconfident about their abilities, they would tend to be less likely to select the risky job. To the extent that this is true, we are systematically underestimating the choice gap attributable to pure differences in risk preferences.

Additional evidence comes from OLS and Random Effects regressions of typing performance in the job choice treatment on our ex ante measure of productivity from the assigned job treatments. The estimated coefficients on our ex ante productivity measure are very nearly equal to 1.00 and highly statistically significant. On the other hand the constant term and subject gender are never statistically significant. The simple $R^{2}$ between typing performance in the job choice treatment and the ex ante productivity measure ranges from 0.90 to $0.95 .^{8}$

Clearly there is no universally accepted measure of risk attitudes. ${ }^{9}$ Nevertheless, the Holt-Laury measure based on lottery choices has enjoyed some status as a widely accepted measure or proxy for risk preferences. While not the central theme of this paper, it was relatively costless to investigate the association between this measure of risk preferences and job choice. The HL measure of risk aversion is consistently negative in its effect on the probability of choosing the risky job, though it is statistically significant with only the combined data from the risk premium experiments. Our view is that the HL measure has some validity but is far from the only or even major determinant of risky vs. secure job choice.

Although the expected unemployment rate in the risky job is set at $\phi=0.3$, the realized unemployment rates for men and women who choose the risky job will generally not equal the expected unemployment rate in finite samples. Gender differences in the sampling errors can affect the $\theta$ weights, and hence the magnitude of the job choice component of

\footnotetext{
${ }^{8}$ These estimation results are available upon request.

${ }^{9}$ See Cox et al. (2013) for a discussion of the theoretical requirements for rationalization of risk attitudes arising from decisions under risk.
} 
the wage decomposition. In the technical appendix we modify the wage decompositions to take explicit account of gender differences in the realized unemployment rates. In the $R P=0.06$ treatment, the realized unemployment rates for men and women are virtually identical to one another and to the expected unemployment rate ( 0.31 for men and 0.32 for women). On the other hand the gender difference in the realized unemployment rates are quite pronounced in the $R P=0.07$ treatment ( 0.25 for men and 0.36 for women). Though not statistically significant, this difference is nevertheless sizable in magnitude. Our modified decomposition for the $R P=0.07$ treatment shows that depending on the decomposition weights, the job choice component of the wage decomposition falls from either $0.20(40 \%)$ to $0.15(30 \%)$ or from $0.26(52 \%)$ to $0.19(38 \%)$. While these results are still a consequence of the decision to choose the risky job, they do illuminate a potentially important factor underlying gender wage gaps arising from gender differences in job choice.

It should be noted that we test for gender differences in risk preferences in only one type of setting, namely the financial risk associated with involuntary spells of unemployment. There are of course other types of risks that influence job choices, e.g. health risks and risks of bodily injury. Gender differences in these other types of risk preferences clearly could exist in the naturally occurring labor market and could further contribute to observed gender wage differentials.

\section{Summary and Conclusions}

The research reported in this paper exploits the tight control of the laboratory environment to examine the potential for gender differences in risk attitudes to contribute to gender wage gaps in the labor market. The mechanism examined here is the selection between a risky job and a secure job defined by a known probability of unemployment in the former and the absence of unemployment in the latter. The risky job entails a risk premium in the piece-rate for accurately typed blocks of letters. Unlike the field environment, there is no wage discrimination, monopsony power, imposed job segregation, or competition in our laboratory setting. Any gender wage gap that arises can only arise from two sources: job performance and job choice. 
In our experiments a gender wage gap arose in both risk premium treatments, and these gaps favored men. The wage gap was $13.6 \%$ of the average female wage in the high premium experiment and $12.3 \%$ of the average female wage in the low risk premium experiment. Women exhibited a greater propensity to choose the secure, but lower paying, job. These choices account for between $40 \%$ and $77 \%$ of the gender wage gap, depending

on the risk premium and which risky job wage payment fraction $\left(\theta_{r}^{f}\right.$ for women or $\theta_{r}^{m}$ for men) is used to weight gender differences in job performance. While the magnitudes of gender wage gaps can be expected to be different in the field because of a whole host of additional factors at work, the experimental evidence in our case points to the potential of risk attitudes for contributing to observed gender wage gaps in naturally occurring labor markets.

Other potential avenues for extension of our work are along the lines of a) conditioning the probability of unemployment on an individual's job performance, and b) the relationship between risk aversion and competition aversion. A note of caution is in order, however. As the literature clearly shows, the notion of risk preference can be an elusive concept. Attitudes towards risky choices are realistically viewed as a bundle of behavioral elements such as overconfidence and optimism in addition to the strict theoretical notion based on the curvature of utility functions with respect to income. The composition of the bundle can be dependent on the particular context. It can be quite difficult, if not impossible, to unbundle these dimensions of risky choices in any given choice situation. At the very least the present study systematically investigates the potential consequences for gender wage gaps that follow from gender differences in choices between financially risky and secure jobs in a setting that abstracts from a variety of confounding influences in naturally occurring labor markets.

\section{References}

Arnot, M., M. David, and G. Weiner (1999). Closing the Gender Gap: Post-war Education and Social Change. Polity Press, Cambridge, UK.

Baldwin, M. L., R. J. Butler, and W. G. Johnson (2001). A Hierarchical Theory of Occu- 
pational Segregation and Wage Discrimination. Economic Inquiry 39(1), 94-110.

Barsky, R. B., F. T. Juster, M. S. Kimball, and M. D. Shapiro (1997). Preference parameters and behavioral heterogeneity: An experimental approach in the health and retirement study. The Quarterly Journal of Economics 112(2), 537-79.

Bayard, K., J. Hellerstein, D. Neumark, and K. Troske (2003). New evidence on sex segregation and sex differences in wages from matched employee-employer data. Journal of Labor Economics 21(4), 887-922.

Bellante, D. and A. N. Link (1981). Are public sector workers more risk averse than private sector workers? Industrial and Labor Relations Review 34(3), 408-412.

Bertrand, M. (2011). New Perspectives on Gender, Volume 4 of Handbook of Labor Economics, Chapter 17, pp. 1543-1590. Elsevier.

Blau, F. D. and L. M. Kahn (1981). Causes and consequences of layoffs. Economic Inquiry 19(2), 270-296.

Bonin, H., T. Dohmen, A. Falk, D. Huffman, and U. Sunde (2007). Cross-sectional earnings risk and occupational sorting: The role of risk attitudes. Labour Economics 14(6), 926937.

Buser, T., M. Niederle, and H. Oosterbeek (2014). Gender, competitiveness, and career choices. The Quarterly Journal of Economics 129(3), 1409-1447.

Buurman, M., J. Delfgaauw, R. Dur, and S. Van den Bossche (2012). Public sector employees: Risk averse and altruistic? Journal of Economic Behavior $\&$ Organization 83(3), 279-291.

Cardenas, J.-C., A. Dreber, E. von Essen, and E. Ranehill (2012). Gender differences in competitiveness and risk taking: Comparing children in Colombia and Sweden. Journal of Economic Behavior 83 Organization 83(1), 11-23.

Cox, J. and R. Oaxaca (1996). Testing job search models: The laboratory approach,. Research in Labor Economics 15, 171-207. 
Cox, J., V. Sadiraj, B. Vogt, and U. Dasgupta (2013, October). Is there a plausible theory for decision under risk? A dual calibration critique. Economic Theory 54(2), 305-333.

Cox, J. C. and R. L. Oaxaca (1989). Laboratory experiments with a finite-horizon jobsearch model. Journal of Risk and Uncertainty 2(3), 301-29.

Cox, J. C. and R. L. Oaxaca (1992). Direct tests of the reservation wage property. The Economic Journal 102(415), pp. 1423-1432.

Croson, R. and U. Gneezy (2009). Gender differences in preferences. Journal of Economic Literature $47(2), 448-74$.

Dohmen, T. and A. Falk (2011). Performance pay and multidimensional sorting: Productivity, preferences, and gender. American Economic Review 101(2), 556-90.

Dohmen, T., A. Falk, D. Huffman, U. Sunde, J. Schupp, and G. G. Wagner (2005). Individual risk attitudes: New evidence from a large, representative, experimentally-validated survey. Discussion Papers of DIW Berlin 511, DIW Berlin, German Institute for Economic Research.

Eckel, C. C. and P. J. Grossman (2008). Men, women and risk aversion: Experimental evidence. Handbook of Experimental Economics Results 1, 1061-1073.

Ekelund, J., E. Johansson, M.-R. Jarvelin, and D. Lichtermann (2005). Self-employment and risk aversion-evidence from psychological test data. Labour Economics 12(5), 649659.

Filippin, A. (2016, May). Gender differences in risk attitudes. IZA World of Labor, 100100.

Filippin, A. and P. Crosetto (2016). A reconsideration of gender differences in risk attitudes. Management Science (2014-01).

Gneezy, U., M. Niederle, and A. Rustichini (2003). Performance in competitive environments: Gender differences. The Quarterly Journal of Economics 118(3), 1049-1074. 
Goerke, L. and M. Pannenberg (2012). Risk aversion and trade-union membership*. The Scandinavian Journal of Economics 114(2), 275-295.

Gysler, M., J. Kruse, and R. Schubert (2002). Ambiguity and gender differences in financial decision making: An experimental examination of competence and confidence effects. CER-ETH Economics working paper series 02/23, CER-ETH - Center of Economic Research (CER-ETH) at ETH Zurich.

Hartog, J., A. Ferrer-i Carbonell, and N. Jonker (2002). Linking measured risk aversion to individual characteristics. Kyklos 55(1), 3-26.

Hartog, J., E. Plug, L. Diaz-Serrano, and J. Vieira (2003). Risk compensation in wages a replication. Empirical Economics 28(3), 639-647.

Holt, C. A. and S. K. Laury (2002). Risk aversion and incentive effects. American Economic Review 92(5), 1644-1655.

Hotchkiss, J. L. and M. M. Pitts (2007, May). The Role of Labor Market Intermittency in Explaining Gender Wage Differentials. American Economic Review 97(2), 417-421.

Jung, S. (2017). Gender wage gap and sample selection via risk atttitudes. International Journal of Manpower 38(2), 318-335.

Kamas, L. and A. Preston (2012). The importance of being confident; gender, career choice, and willingness to compete. Journal of Economic Behavior and Organization 83(1), 8297.

Levin, I. P., M. A. Snyder, and D. P. Chapman (1988). The interaction of experiential and situational factors and gender in a simulated risky decision-making task. The Journal of Psychology 122(2), 173-181.

Moore, M. J. (1995). Unions, employment risks, and market provision of employment risk differentials. Journal of Risk and Uncertainty 10(1), 57-70.

Murphy, K. M., R. H. Topel, K. Lang, and J. S. Leonard (1987). Unemployment, risk, and earnings: Testing for equalizing wage differences in the labor market. In K. Lang and 
J. S. Leonard (Eds.), Unemployment and the Structure of Labor Markets, pp. 103-140. New York: Basil Blackwell.

Niederle, M. and L. Vesterlund (2007). Do women shy away from competition? do men compete too much? The Quarterly Journal of Economics 122(3), 1067-1101.

Niederle, M. and L. Vesterlund (2011). Gender and competition. Annual Review in Economics 3, 601-630.

Oaxaca, R. (1973, October). Male-Female Wage Differentials in Urban Labor Markets. International Economic Review 14(3), 693-709.

Pannenberg, M. (2007). Risk aversion and reservation wages. IZA Discussion Papers 2806, Institute for the Study of Labor (IZA).

Petrie, R. and C. Segal (2017). Gender differences in competitiveness: The role of prizes. Working Paper.

Pfeifer, C. (2011). Risk aversion and sorting into public sector employment. German Economic Review 12(1), 85-99.

Pissarides, C. A. (1974). Risk, job search, and income distribution. Journal of Political Economy 82(6), 1255-67.

Schubert, R. (1999, May). Financial Decision-Making: Are Women Really More RiskAverse? American Economic Review 89(2), 381-385.

Shatnawi, D., R. Oaxaca, and M. Ransom (2014). Movin' on up: Hierarchical occupational segmentation and gender wage gaps. Journal of Economic Inequality 12(3), 315-338.

Smith, A. (1776). An Inquiry into the Nature and Causes of the Wealth of the Nations. London: W. Strahan and T. Cadell.

Wilkins, R. and M. Wooden (2013). Gender differences in involuntary job loss: Why are men more likely to lose their jobs? Industrial Relations: A Journal of Economy and Society 52(2), 582-608. 
Table 1: Descriptive Statistics

\begin{tabular}{lcccccc}
\hline \hline & \multicolumn{2}{c}{ Men } & \multicolumn{2}{c}{ Women } & \multicolumn{2}{c}{ Diff } \\
& mean & s.e. & mean & s.e. & mean & s.e. \\
\hline Personal & & & & & & \\
Age & 23.35 & $(0.32)$ & 23.54 & $(0.50)$ & -0.19 & $(0.57)$ \\
Risk Aversion (HL) & 6.17 & $(0.18)$ & 6.08 & $(0.23)$ & 0.10 & $(0.29)$ \\
Experimental & & & & & & \\
Productivity & 23.54 & $(0.59)$ & 22.89 & $(0.55)$ & $1.39^{*}$ & $(0.82)$ \\
Unemployment History & 0.31 & $(0.01)$ & 0.31 & $(0.02)$ & -0.01 & $(0.02)$ \\
Risky Choice & 0.75 & $(0.04)$ & 0.6 & $(0.05)$ & $0.15^{* *}$ & $(0.07)$ \\
\hline obs & 103 & & 89 & & & \\
\hline \hline
\end{tabular}

Notes: ${ }^{*} p<0.1,{ }^{* *} p<0.05, * * * p<0.01$. Standard errors in parentheses.

Two-tailed t-tests are performed for the difference between men and women.

Table 2: Productivity (Number of correctly typed words): Risk Premium=0.07

\begin{tabular}{lcccc|cccc}
\hline \hline & \multicolumn{4}{c|}{ Assigned } & \multicolumn{4}{c}{ Choice } \\
& Overall & Risky & Secure & $\bar{P}_{r}-\bar{P}_{s}$ & Overall & Risky & Secure & $\bar{P}_{r}-\bar{P}_{s}$ \\
\hline Men & 23.21 & 23.10 & 23.28 & -0.18 & 23.31 & 23.26 & 23.42 & -0.16 \\
& $(0.08)$ & $(0.11)$ & $(0.1)$ & $(0.15)$ & $(0.1)$ & $(0.11)$ & $(0.19)$ & $(0.22)$ \\
obs & 925 & 385 & 540 & & 439 & 309 & 130 & \\
\hline Women & 21.67 & 21.54 & 21.76 & -0.22 & 22.07 & 21.29 & 23.00 & $-1.71^{* * *}$ \\
& $(0.08)$ & $(0.12)$ & $(0.1)$ & $(0.16)$ & $(0.12)$ & $(0.16)$ & $(0.17)$ & $(0.23)$ \\
obs & 729 & 299 & 430 & & 328 & 178 & 150 & \\
\hline $\bar{P}^{m}-\bar{P}^{f}$ & $1.54^{* * *}$ & $1.56^{* * *}$ & $1.52^{* * *}$ & 0.04 & $1.24^{* * *}$ & $1.97^{* * *}$ & 0.42 & $1.55^{* * *}$ \\
& $(0.11)$ & $(0.16)$ & $(0.14)$ & $(0.22)$ & $(0.16)$ & $(0.19)$ & $(0.25)$ & $(0.32)$ \\
\hline \hline
\end{tabular}

Notes: ${ }^{*} p<0.1,{ }^{* *} p<0.05,{ }^{* * *} p<0.01$. Standard errors in differences are calculated as the square root of the sum of squared S.E. from the fixed effects model.

Table 3: Wage: Risk Premium $=0.07$

\begin{tabular}{lcccc|cccc}
\hline \hline & \multicolumn{4}{c|}{ Assigned } & \multicolumn{4}{c}{ Choice } \\
& Overall & Risky & Secure & $\bar{W}_{r}-\bar{W}_{s}$ & Overall & Risky & Secure & $\bar{W}_{r}-\bar{W}_{s}$ \\
\hline Men & 3.78 & 4.62 & 3.03 & $1.59^{* * *}$ & 4.18 & 4.65 & 3.04 & $1.61^{* * *}$ \\
& $(0.01)$ & $(0.02)$ & $(0.01)$ & $(0.02)$ & $(0.02)$ & $(0.02)$ & $(0.03)$ & $(0.04)$ \\
obs & 925 & 385 & 540 & & 439 & 309 & 130 & \\
\hline Women & 3.44 & 4.31 & 2.83 & $1.48^{* * *}$ & 3.68 & 4.26 & 2.99 & $1.27^{* * *}$ \\
& $(0.01)$ & $(0.02)$ & $(0.01)$ & $(0.02)$ & $(0.02)$ & $(0.03)$ & $(0.02)$ & $(0.04)$ \\
obs & 729 & 299 & 430 & & 328 & 178 & 150 & \\
\hline $\bar{W}^{m}-\bar{W}^{f}$ & $0.34^{* * *}$ & $0.31^{* * *}$ & $0.20^{* * *}$ & $0.11^{* * *}$ & $0.50^{* * *}$ & $0.39^{* * *}$ & 0.05 & $0.34^{* * *}$ \\
& $(0.01)$ & $(0.03)$ & $(0.01)$ & $(0.03)$ & $(0.03)$ & $(0.04)$ & $(0.04)$ & $(0.05)$ \\
\hline \hline
\end{tabular}

Notes: $* p<0.1,{ }^{* *} p<0.05,{ }^{* * *} p<0.01$. Standard errors in differences are calculated as the square root of the sum of squared S.E. from the fixed effects model. 
Table 4: Productivity (Number of correctly typed words): Risk Premium $=0.06$

\begin{tabular}{lcccc|cccc}
\hline \hline & \multicolumn{4}{c|}{ Assigned } & \multicolumn{4}{c}{ Choice } \\
& Overall & Risky & Secure & $\bar{P}_{r}-\bar{P}_{s}$ & Overall & Risky & Secure & $\bar{P}_{r}-\bar{P}_{s}$ \\
\hline Men & 23.94 & 24.09 & 23.84 & 0.25 & 24.18 & 23.13 & 26.18 & $-3.05^{* * *}$ \\
& $(0.08)$ & $(0.12)$ & $(0.11)$ & $(0.16)$ & $(0.1)$ & $(0.13)$ & $(0.16)$ & $(0.21)$ \\
obs & 819 & 329 & 490 & & 378 & 248 & 130 & \\
\hline Women & 22.71 & 22.98 & 22.52 & $0.46^{* * *}$ & 22.8 & 23.84 & 21.95 & $1.89^{* * *}$ \\
& $(0.08)$ & $(0.13)$ & $(0.11)$ & $(0.17)$ & $(0.11)$ & $(0.18)$ & $(0.14)$ & $(0.23)$ \\
obs & 771 & 311 & 460 & & 380 & 170 & 210 & \\
\hline $\bar{P}^{m}-\bar{P}^{f}$ & $1.23^{* * *}$ & $1.11^{* * *}$ & $1.32^{* * *}$ & -0.21 & $1.38^{* * *}$ & $-0.71^{* * *}$ & $4.23^{* * *}$ & $-4.94^{* * *}$ \\
& $(0.11)$ & $(0.18)$ & $(0.16)$ & $(0.24)$ & $(0.15)$ & $(0.22)$ & $(0.21)$ & $(0.31)$ \\
\hline \hline
\end{tabular}

Notes: ${ }^{*} p<0.1,{ }^{* *} p<0.05,{ }^{* * *} p<0.01$. Standard errors are in parentheses. Standard errors in differences are calculated as the square root of the sum of squared S.E. from the fixed effects model.

Table 5: Wage: Risk Premium $=0.06$

\begin{tabular}{lcccc|cccc}
\hline \hline & \multicolumn{4}{c|}{ Assigned } & \multicolumn{4}{c}{ Choice } \\
& Overall & Risky & Secure & $\bar{W}_{r}-\bar{W}_{s}$ & Overall & Risky & Secure & $\bar{W}_{r}-\bar{W}_{s}$ \\
\hline Men & 3.93 & 4.82 & 3.34 & $1.48^{* * *}$ & 4.30 & 4.63 & 3.67 & $0.96^{* * *}$ \\
& $(0.01)$ & $(0.02)$ & $(0.01)$ & $(0.02)$ & $(0.02)$ & $(0.03)$ & $(0.02)$ & $(0.04)$ \\
obs & 819 & 329 & 490 & & 378 & 248 & 130 & \\
\hline Women & 3.74 & 4.60 & 3.15 & $1.45^{* * *}$ & 3.83 & 4.77 & 3.07 & $1.70^{* * *}$ \\
& $(0.01)$ & $(0.03)$ & $(0.02)$ & $(0.04)$ & $(0.02)$ & $(0.04)$ & $(0.02)$ & $(0.04)$ \\
obs & 771 & 311 & 460 & & 380 & 170 & 210 & \\
\hline $\bar{W}^{m}-\bar{W}^{f}$ & $0.19^{* * *}$ & $0.22^{* * *}$ & $0.19^{* * *}$ & 0.03 & $0.47^{* * *}$ & $-0.14^{* * *}$ & $0.60^{* * *}$ & $-0.74^{* * *}$ \\
& $(0.01)$ & $(0.04)$ & $(0.02)$ & $(0.04)$ & $(0.03)$ & $(0.05)$ & $(0.03)$ & $(0.06)$ \\
\hline \hline
\end{tabular}

Notes: $* p<0.1,{ }^{* *} p<0.05, * * * p<0.01$. Standard errors are in parentheses. Standard errors in differences are calculated as the square root of the sum of squared S.E. from the fixed effects model. 
Table 6: Gender Differences in Job Choices

\begin{tabular}{lcccccc}
\hline \hline & \multicolumn{2}{c}{$\mathrm{RP}=0.07$} & \multicolumn{2}{c}{$\underline{\mathrm{RP}=0.06}$} & \multicolumn{2}{c}{$\underline{\text { Combined }}$} \\
& $\mathrm{n}$ & $\theta_{r}$ & $\mathrm{n}$ & $\theta_{r}$ & $\mathrm{n}$ & $\theta_{r}$ \\
\hline Men & 0.76 & 0.70 & 0.73 & 0.66 & 0.75 & 0.68 \\
& $(0.06)$ & $(0.06)$ & $(0.06)$ & $(0.07)$ & $(0.04)$ & $(0.05)$ \\
obs & 54 & 439 & 49 & 378 & 103 & 817 \\
\hline Women & 0.65 & 0.54 & 0.54 & 0.45 & 0.6 & 0.49 \\
& $(0.07)$ & $(0.07)$ & $(0.08)$ & $(0.08)$ & $(0.05)$ & $(0.05)$ \\
obs & 43 & 328 & 46 & 380 & 89 & 708 \\
\hline Diff & 0.11 & 0.16 & $0.19^{*}$ & $0.21^{* *}$ & $0.15^{* *}$ & $0.19^{* * *}$ \\
& $(0.09)$ & $(0.10)$ & $(0.10)$ & $(0.10)$ & $(0.07)$ & $(0.07)$ \\
\hline \hline
\end{tabular}

Notes: ${ }^{*} p<0.1,{ }^{* *} p<0.05,{ }^{* * *} p<0.01$. Standard errors are in parentheses. Standard errors are in parentheses. $n$ : proportion of individuals in group $j$ who selected the risky job. $\theta_{r}$ : proportion of wage payments in group $j$ arising from the (selected) risky job.

Table 7: Inferred Risk Attitudes

\begin{tabular}{lcccccc}
\hline \hline & \multicolumn{2}{c}{$\underline{\mathrm{RP}=0.07}$} & \multicolumn{2}{c}{$\underline{\mathrm{RP}=0.06}$} & \multicolumn{2}{c}{ Combined } \\
& Men & Women & Men & Women & Men & Women \\
\hline Identified Risk Averse & $24 \%$ & $35 \%$ & $27 \%$ & $46 \%$ & $25 \%$ & $40 \%$ \\
Identified Risk Loving & $0 \%$ & $0 \%$ & $0 \%$ & $0 \%$ & $0 \%$ & $0 \%$ \\
Not Identified & $76 \%$ & $65 \%$ & $73 \%$ & $54 \%$ & $75 \%$ & $60 \%$ \\
\hline Total & $100 \%$ & $100 \%$ & $100 \%$ & $100 \%$ & $100 \%$ & $100 \%$ \\
obs & 54 & 43 & 49 & 46 & 103 & 89 \\
\hline \hline
\end{tabular}


Table 8: Wage Decompositions for Job Choices

\begin{tabular}{lccccccc}
\hline \hline & \multicolumn{2}{c}{$R P=0.07$} & & \multicolumn{2}{c}{$R P=0.06$} & & \multicolumn{2}{c}{ Combined } \\
& $\theta_{r}^{f}$ & $\theta_{r}^{m}$ & & $\theta_{r}^{f}$ & $\theta_{r}^{m}$ & $\theta_{r}^{f}$ & $\theta_{r}^{m}$ \\
\hline Productivity & 0.24 & 0.29 & 0.26 & 0.11 & 0.25 & 0.21 \\
Job Choice & 0.26 & 0.20 & & 0.20 & 0.36 & 0.23 & 0.27 \\
Experiment Weight Diff & & & & & -0.01 & -0.01 \\
Rounding Error & 0.00 & 0.01 & & 0.01 & 0.00 & 0.01 & 0.01 \\
\hline Wage Gap & \multicolumn{2}{c}{0.50} & \multicolumn{2}{c}{0.47} & \multicolumn{2}{c}{0.48} \\
\hline \hline
\end{tabular}

Notes: $\theta_{r}^{f}$ and $\theta_{r}^{m}$ are the proportions of wage payments for women and men arising from the (selected) risky job. The Combined decompositions use $\Omega^{m}$ to weight the decompositions arising from the two risk premium experiments. 'Experiment Weight Diff' is $\left[w_{f}^{(1)}-w_{f}^{(2)}\right]\left(\Omega_{m}-\Omega_{f}\right)$

Table 9: Probit Selection Equation for 'Risky Job'

\begin{tabular}{lccc}
\hline \hline & Overall & $\mathrm{RP}=0.07$ & $\mathrm{RP}=0.06$ \\
\hline Female & $-0.492^{* *}$ & -0.396 & $-0.602^{* *}$ \\
Age & $(0.20)$ & $(0.29)$ & $(0.28)$ \\
& 0.007 & -0.035 & 0.040 \\
Risk Aversion (HL) & $(0.03)$ & $(0.04)$ & $(0.04)$ \\
& $-0.093^{* *}$ & $-0.115^{*}$ & -0.087 \\
Productivity & $(0.05)$ & $(0.07)$ & $(0.07)$ \\
& -0.023 & -0.054 & -0.014 \\
Unemployment History & $(0.02)$ & $(0.04)$ & $(0.02)$ \\
& $-2.635^{* * *}$ & $-2.472^{* *}$ & $-2.827^{* * *}$ \\
Risky jobs before Choice & $(0.69)$ & $(1.03)$ & $(1.01)$ \\
& 0.082 & -0.155 & 0.237 \\
Risk Premium (0.07) & $(0.20)$ & $(0.30)$ & $(0.29)$ \\
& 0.075 & & \\
Constant & $(0.20)$ & & \\
& $2.419^{* *}$ & $4.312^{* *}$ & 1.461 \\
chi2 & $(1.10)$ & $(1.98)$ & $(1.32)$ \\
$\mathrm{N}$ & 25.65 & 11.97 & 15.35 \\
\hline \hline
\end{tabular}

Notes: ${ }^{*} p<0.1,{ }^{* *} p<0.05,{ }^{* * *} p<0.01$. Standard errors in parentheses. 'Productivity': average productivity over the last observed five periods in the assigned treatment. 'Unemployment History': average number of unemployment periods in the assigned risky session. 'Risky jobs before Choice': a dummy variable for experiencing the risky job type in the second session, before the choice decision. 


\section{Technical Appendix}

\section{TA1. Decomposition Analysis}

Our objective is to be able to measure the effect of gender differences in job choice on any gender wage gaps that arise within our experimental setting. This is accomplished through decomposition methods. We begin with the within-job gender wage gaps and then consider the effects of job choices.

secure job

Let $w_{s, i}^{j}$ represent the average wage of the $i$ th worker from group $j=m, f$ in the secure job:

$$
\begin{aligned}
w_{s, i}^{j}= & \frac{\sum_{t=1}^{T} w_{s, i t}^{j}}{T} \\
= & \frac{\gamma_{s} \sum_{t=1}^{T} P_{s, i t}^{j}}{T} \\
= & \gamma_{s} P_{s, i}^{j}
\end{aligned}
$$

where $T=10$, and $P_{s, i}^{j}=$ the average performance/productivity of the $i$ th worker.

The average wage over all workers in group $j$ in the secure job is simply

$$
w_{s}^{j}=\frac{\sum_{i=1}^{N_{s}^{j}} w_{s, i}^{j}}{N_{s}^{j}}=\frac{\gamma_{s} \sum_{i=1}^{N_{s}^{j}} P_{s, i}^{j}}{N_{s}^{j}}=\gamma_{s} P_{s}^{j},
$$

where $N_{s}^{j}=$ is the number of workers in group $j$ in the secure job, and $P_{s}^{j}=$ the average performance of group $j$ workers in the secure job, i.e.

$$
P_{s}^{j}=\frac{\sum_{i=1}^{N_{s}^{j}} P_{s, i}^{j}}{N_{s}^{j}}=\frac{\sum_{i=1}^{N_{s}^{j}} \sum_{t=1}^{T} P_{s, i t}^{j}}{N_{s}^{j} T} .
$$


The gender wage decomposition for the secure job is simply

$$
w_{s}^{m}-w_{s}^{f}=\gamma_{s}\left(P_{s}^{m}-P_{s}^{f}\right)
$$

This illustrates that the only source of a gender wage gap within a given job arises from gender differences in productivity.

\section{risky job}

Wage decompositions within the risky job are calculated only over the observations for which individuals are employed. We define an indicator for employment as

$E_{i t}=1$ (employed). Let $w_{r, i}^{j}$ represent the conditional average wage of the $i$ th worker from group $j=m, f$ in the risky job:

$$
w_{r, i}^{j}=\frac{\sum_{t \epsilon\left\{E_{i t}=1\right\}} w_{r, i t}^{j}}{T_{r, i}^{j}}=\frac{\gamma_{r} \sum_{t \epsilon\left\{E_{i t}=1\right\}} P_{r, i t}^{j}}{T_{r, i}^{j}}=\gamma_{r} P_{r, i}^{j},
$$

where $T_{r, i}^{j} \leq T$ is the number of periods for which the $i$ th worker was employed in the risky job, and

$$
P_{r, i}^{j}=\frac{\sum_{t \epsilon\left\{E_{i t}=1\right\}} P_{r, i t}^{j}}{T_{r, i}^{j}}
$$

is the individual's performance averaged over their periods of employment.

The conditional average wage over all workers in group $j$ in the risky job is accordingly

$$
w_{r}^{j}=\frac{\sum_{i=1}^{N_{r}^{j}} \sum_{t \epsilon\left\{E_{i t}=1\right\}} w_{r, i t}^{j}}{\sum_{i=1}^{N_{r}^{j}} T_{r, i}^{j}}=\frac{\gamma_{r} \sum_{i=1}^{N_{r}^{j}} \sum_{t \epsilon\left\{E_{i t}=1\right\}} P_{r, i t}^{j}}{\sum_{i=1}^{N_{r}^{m}} T_{r, i}^{j}}=\gamma_{r} P_{r}^{j}
$$

where $P_{r}^{j}$ is average performance for all subjects in group $j$ over all spells of employment in the risky job.

It follows that the gender wage decomposition for the risky job is

$$
w_{r}^{m}-w_{r}^{f}=\gamma_{r}\left(P_{r}^{m}-P_{r}^{f}\right) .
$$


Again, the only sources of a gender wage gap within a job arise from gender differences in performance.

\section{endogenous job choice}

Ultimately, we are interested in how gender differences in choosing between secure and risky jobs impact gender wage gaps.

The average wage for group $j=m, f$ across both the secure and risky jobs is calculated as

$$
\begin{aligned}
w_{j} & =w_{r}^{j} \theta_{r}^{j}+w_{s}^{j}\left(1-\theta_{r}^{j}\right) \\
& =\gamma_{r} P_{r}^{j} \theta_{r}^{j}+\gamma_{s} P_{s}^{j}\left(1-\theta_{r}^{j}\right)
\end{aligned}
$$

where $\theta_{r}^{j}$ is the sample proportion of the observations generated from the risky job choices, i.e.

$$
\theta_{r}^{j}=\frac{\sum_{i=1}^{N_{r}^{j}} T_{r, i}^{j}}{N_{s}^{j} T+\sum_{i=1}^{N_{r}^{j}} T_{r, i}^{j}} .
$$

For a given risk premium within the endogenous choice treatment (Treatment 3), the gender wage gap decomposition may be expressed by

$$
\begin{aligned}
w_{m}-w_{f} & =\underbrace{\gamma_{r}\left(P_{r}^{m}-P_{r}^{f}\right) \theta_{r}^{f}+\gamma_{s}\left(P_{s}^{m}-P_{s}^{f}\right)\left(1-\theta_{r}^{f}\right)}_{\text {productivity }} \\
& +\underbrace{\left(\gamma_{r} P_{r}^{m}-\gamma_{s} P_{s}^{m}\right)\left(\theta_{r}^{m}-\theta_{r}^{f}\right)}_{\text {job choice }},
\end{aligned}
$$

or alternatively by

$$
\begin{aligned}
w_{m}-w_{f} & =\underbrace{\gamma_{r}\left(P_{r}^{m}-P_{r}^{f}\right) \theta_{r}^{m}+\gamma_{s}\left(P_{s}^{m}-P_{s}^{f}\right)\left(1-\theta_{r}^{m}\right)}_{\text {productivity }} \\
& +\underbrace{\left(\gamma_{r} P_{r}^{f}-\gamma_{s} P_{s}^{f}\right)\left(\theta_{r}^{m}-\theta_{r}^{f}\right)}_{\text {job choice }} .
\end{aligned}
$$


The alternative decompositions arise from weighting the gender differences in productivity, $\left(P_{r}^{m}-P_{r}^{f}\right)$ and $\left(P_{s}^{m}-P_{s}^{f}\right)$ by either $\theta_{r}^{f}$ or $\theta_{r}^{m}$.

With two sets of experiments corresponding to two different risk premiums, we can perform aggregate decompositions that combine the two sets of experiments. For simplicity we will denote the two risk premium experiments as (1) and (2), which correspond to risk premiums of $€ 0.07$ and $€ 0.06$, respectively .

The weight for risk premium experiment (1) for group $j=m, f$ is

$$
\Omega_{j}=\frac{N_{s}^{j(1)} T+\sum_{i=1}^{N_{r}^{j(1)}} T_{r, i}^{j(1)}}{\left[N_{s}^{j(1)} T+\sum_{i=1}^{N_{r}^{j(1)}} T_{r, i}^{j(1)}\right]+\left[N_{s}^{j(2)} T+\sum_{i=1}^{N_{r}^{j(2)}} T_{r, i}^{j(2)}\right]}
$$

Therefore, the weighted average wage over both sets of experiments for group $j$ is given by

$$
w_{j}=w_{j}^{(1)} \Omega_{j}+\left(1-\Omega_{j}\right) w_{j}^{(2)}
$$

When considering a decomposition of the overall gender wage gap for the two sets of risk premium experiments combined, four alternatives readily come to mind. These are derived from the sample weights from the two risk premium experiments $(\Omega)$ interacted with the share of each gender group's observations from selection of the risky job $\left(\theta_{r}\right)$ : $\left(\Omega^{m}, \theta_{r}^{f}\right),\left(\Omega^{m}, \theta_{r}^{m}\right),\left(\Omega^{f}, \theta_{r}^{f}\right),\left(\Omega^{f}, \theta_{r}^{m}\right)$.

Conditioning on the choice of $\theta_{r}$, we obtain two possible decompositions:

$$
\begin{aligned}
w_{m}-w_{f} & =\left[w_{m}^{(1)}-w_{f}^{(1)}\right] \Omega_{m}+\left[w_{m}^{(2)}-w_{f}^{(2)}\right]\left(1-\Omega_{m}\right) \\
& +\left[w_{f}^{(1)}-w_{f}^{(2)}\right]\left(\Omega_{m}-\Omega_{f}\right)
\end{aligned}
$$

and

$$
\begin{aligned}
w_{m}-w_{f} & =\left[w_{m}^{(1)}-w_{f}^{(1)}\right] \Omega_{f}+\left[w_{m}^{(2)}-w_{f}^{(2)}\right]\left(1-\Omega_{f}\right) \\
& +\left[w_{m}^{(1)}-w_{m}^{(2)}\right]\left(\Omega_{m}-\Omega_{f}\right) .
\end{aligned}
$$


The portion of the overall wage gap arising from the gender wage gaps in each of the two sets of experiments is measured by $\left[w_{m}^{(1)}-w_{f}^{(1)}\right] \Omega_{m}+\left[w_{m}^{(2)}-w_{f}^{(2)}\right]\left(1-\Omega_{m}\right)$ or by $\left[w_{m}^{(1)}-w_{f}^{(1)}\right] \Omega_{f}+\left[w_{m}^{(2)}-w_{f}^{(2)}\right]\left(1-\Omega_{f}\right)$. The terms $\left[w_{f}^{(1)}-w_{f}^{(2)}\right]\left(\Omega_{m}-\Omega_{f}\right)$ and $\left[w_{m}^{(1)}-w_{m}^{(2)}\right]\left(\Omega_{m}-\Omega_{f}\right)$ reflect the difference in sample weights for the two experiments weighted by the average wage difference among women or men between the two sets of experiments.

As an example of the contributions of gender differences in productivity and job choice to the overall wage gaps from our two sets of experiments, we confine our attention to the decomposition corresponding to $\left(\Omega^{m}, \theta_{r}^{f}\right)$. The other alternative decompositions are obtained in an analogous fashion. By appropriate substitution for the average wages in $\left[w_{m}^{(1)}-w_{f}^{(1)}\right] \Omega_{m}+\left[w_{m}^{(2)}-w_{f}^{(2)}\right]\left(1-\Omega_{m}\right)$, we obtain

$$
\begin{aligned}
& \text { productivity }=\left[\gamma_{r}^{(1)}\left(P_{r}^{m(1)}-P_{r}^{f(1)}\right) \theta_{r}^{f(1)}\right. \\
&\left.+\gamma_{s}^{(1)}\left(P_{s}^{m(1)}-P_{s}^{f(1)}\right)\left(1-\theta_{r}^{f(1)}\right)\right] \Omega_{m} \\
&+\left[\gamma_{r}^{(2)}\left(P_{r}^{m(2)}-P_{r}^{f(2)}\right) \theta_{r}^{f(2)}\right. \\
&\left.+\gamma_{s}^{(2)}\left(P_{s}^{m(2)}-P_{s}^{f(2)}\right)\left(1-\theta_{r}^{f(2)}\right)\right]\left(1-\Omega_{m}\right) \\
& \text { job choice }=\left(\gamma_{r}^{(1)} P_{r}^{m(1)}-\gamma_{s}^{(1)} P_{s}^{m(1)}\right)\left(\theta_{r}^{m(1)}-\theta_{r}^{f(1)}\right) \Omega_{m} \\
&+\left(\gamma_{r}^{(2)} P_{r}^{m(2)}-\gamma_{s}^{(2)} P_{s}^{m(2)}\right)\left(\theta_{r}^{m(2)}-\theta_{r}^{f(2)}\right)\left(1-\Omega_{m}\right) .
\end{aligned}
$$

\section{TA2. Gender Differences in Sampling Errors for Unemployment Spells}

The calculations below are based on the figures we report in Table 6 .

\section{$\mathbf{R P}=\mathbf{0 . 0 7}$}

For job choice treatment 3 there were $N^{m}=54$ men and $N^{f}=43$ women. Of the 54 men in treatment 3 , there were $N_{r}^{m}=41(76 \%)$ who selected the risky job. Of the 43 women in treatment 3 , there were $N_{r}^{f}=28(65 \%)$ who selected the risky job. The expected number 
of wage observations for those who selected the risky job are given by

$$
\begin{aligned}
\left(N_{r}^{m}\right)(10)(1-\phi) & =(41)(10)(1-0.3) \\
& =287 \\
\left(N_{r}^{f}\right)(10)(1-\phi) & =(28)(10)(1-0.3) \\
& =196
\end{aligned}
$$

We can back out the estimated incidence of unemployment from the actual observed number of wage observations for those who selected the risky job. Note that the 439 wage observations for men and the 328 observations for women include both those for the secure job and the risky job. The number of wage observations corresponding to the risky job are simply calculated as $439-(10)(54-41)=309$ for men, and $328-(10)(43-28)=178$ for women. So we can now calculate the realized unemployment rates:

$$
\begin{aligned}
\left(N_{r}^{m}\right)(10)\left(1-\hat{\phi}_{m}\right)= & (41)(10)\left(1-\hat{\phi}_{m}\right)=309 \\
& \Rightarrow \hat{\phi}_{m}=1-\frac{309}{410}=0.246 \\
\left(N_{r}^{f}\right)(10)\left(1-\hat{\phi}_{f}\right)= & (28)(10)\left(1-\hat{\phi}_{f}\right)=178 \\
& \Rightarrow \hat{\phi}_{f}=1-\frac{178}{280}=0.364
\end{aligned}
$$

The actual incidence of unemployment spells is less than the expected value for men and greater than the expected value women. Therefore, the realized unemployment rate is higher for women. We can test whether or not the difference is statistically significant. The variance of the difference in sample proportions is given by

$$
\begin{aligned}
\sigma_{\hat{\phi}_{f}-\hat{\phi}_{m}}^{2} & =(\phi)(1-\phi)\left(\frac{1}{N_{r}^{f}}+\frac{1}{N_{r}^{m}}\right) \\
& =(0.3)(0.7)\left(\frac{1}{28}+\frac{1}{41}\right) \\
& =0.013 .
\end{aligned}
$$


The standard error is obtained as

$$
\begin{aligned}
\sigma_{\hat{\phi}_{f}-\hat{\phi}_{m}} & =\sqrt{\sigma_{\hat{\phi}_{f}-\hat{\phi}_{m}}^{2}} \\
& =\sqrt{0.013} \\
& =0.114 .
\end{aligned}
$$

The z score is simply

$$
\begin{aligned}
z & =\frac{\hat{\phi}_{f}-\hat{\phi}_{m}}{\sigma_{\hat{\phi}_{f}-\hat{\phi}_{m}}} \\
& =\frac{0.364-0.246}{0.114} \\
& =1.035 .
\end{aligned}
$$

Thus, the gender difference in realized unemployment rates is not statistically significant for $\mathrm{RP}=0.07$.

\section{$\mathrm{RP}=0.06$}

For job choice treatment 3 there were $N^{m}=49$ men and $N^{f}=46$ women. Of the 49 men in treatment 3 , there were $N_{r}^{m}=36(73 \%)$ who selected the risky job. Of the 46 women in treatment 3 , there were $N_{r}^{f}=25(54 \%)$ who selected the risky job. The expected number of wage observations for those who selected the risky job are given by

$$
\begin{aligned}
\left(N_{r}^{m}\right)(10)(1-\phi) & =(36)(10)(1-0.3) \\
& =252 \\
\left(N_{r}^{f}\right)(10)(1-\phi) & =(25)(10)(1-0.3) \\
& =175
\end{aligned}
$$

We can back out the estimated incidence of unemployment from the actual observed number of wage observations for those who selected the risky job. Note that the 378 wage 
observations for men and the 380 observations for women include both those for the secure job and the risky job. The number of wage observations corresponding to the risky job are simply calculated as $378-(10)(49-36)=248$ for men, and $380-(10)(46-25)=170$ for women. So we can now calculate the realized unemployment rates:

$$
\begin{aligned}
&\left(N_{r}^{m}\right)(10)\left(1-\hat{\phi}_{m}\right)=(36)(10)\left(1-\hat{\phi}_{m}\right)=248 \\
& \Rightarrow \hat{\phi}_{m}=1-\frac{248}{360}=0.311 \\
&\left(N_{r}^{f}\right)(10)\left(1-\hat{\phi}_{f}\right)=(25)(10)\left(1-\hat{\phi}_{f}\right)=170 \\
& \Rightarrow \hat{\phi}_{f}=1-\frac{170}{250}=0.320
\end{aligned}
$$

The actual incidence of unemployment spells is very nearly the same as the expected value for both men and women. The realized unemployment rate is marginally higher for women. We can test whether or not this difference is statistically significant. The variance of the difference in sample proportions is given by

$$
\begin{aligned}
\sigma_{\hat{\phi}_{f}-\hat{\phi}_{m}}^{2} & =(\phi)(1-\phi)\left(\frac{1}{N_{f}}+\frac{1}{N_{m}}\right) \\
& =(0.3)(0.7)\left(\frac{1}{25}+\frac{1}{36}\right) \\
& =0.014
\end{aligned}
$$

The standard error is obtained as

$$
\begin{aligned}
\sigma_{\hat{\phi}_{f}-\hat{\phi}_{m}} & =\sqrt{\sigma_{\hat{\phi}_{f}-\hat{\phi}_{m}}^{2}} \\
& =\sqrt{0.014} \\
& =0.118
\end{aligned}
$$


The $\mathrm{z}$ score is simply

$$
\begin{aligned}
z & =\frac{\hat{\phi}_{f}-\hat{\phi}_{m}}{\sigma_{\hat{\phi}_{f}-\hat{\phi}_{m}}} \\
& =\frac{0.320-0.311}{0.118} \\
& =0.076
\end{aligned}
$$

Thus, the gender difference in realized unemployment rates is not statistically significant for $R P=0.06$.

\section{Wage Decompositions and Sampling Error}

While the realized unemployment rates for both men and women were virtually identical to each other and to the true unemployment rate probability in the $R P=0.06$ treatment, the unemployment rate differences are more pronounced in the $R P=0.07$ treatment. For the $R P=0.07$ treatment, we can correct the wage decompositions for sampling error in the unemployment rate spells.

Note that

$$
\sum_{i=1}^{N_{r}^{m}} T_{r, i}^{m}=\left(N_{r}^{m} T\right)\left(1-\hat{\phi}_{m}\right)
$$

and

$$
\sum_{i=1}^{N_{r}^{f}} T_{r, i}^{f}=\left(N_{r}^{f} T\right)\left(1-\hat{\phi}_{f}\right) .
$$

Accordingly,

$$
\begin{aligned}
\theta_{r}^{m} & =\frac{\sum_{i=1}^{N_{r}^{f}} T_{r, i}^{f}}{N_{s}^{m} T+\sum_{i=1}^{N_{r}^{f}} T_{r, i}^{f}} \\
= & \frac{\left(N_{r}^{m} T\right)\left(1-\hat{\phi}_{m}\right)}{N_{s}^{m} T+\left(N_{r}^{m} T\right)\left(1-\hat{\phi}_{m}\right)} \\
= & \frac{1}{\frac{N_{s}^{m}}{\left(N_{r}^{m}\right)\left(1-\hat{\phi}_{m}\right)}+1} .
\end{aligned}
$$


In the present case

$$
\begin{aligned}
N_{s}^{m} & =N^{m}-N_{r}^{m} \\
& =54-41=13 \\
N_{s}^{f} & =N^{f}-N_{r}^{f} \\
& =43-28=15 .
\end{aligned}
$$

The expected proportions of wage observations for men $\left(\tilde{\theta}_{r}^{m}\right)$ and women $\left(\tilde{\theta}_{r}^{f}\right)$ are obtained by substituting true $\phi$ for $\hat{\phi}_{m}$ and $\hat{\phi}_{f}$ :

$$
\begin{aligned}
\tilde{\theta}_{r}^{m} & =\frac{1}{\frac{N_{s}^{m}}{\left(N_{r}^{m}\right)(1-\phi)}+1} \\
& =\frac{1}{\frac{13}{(41)(1-0.3)+1}} \\
& =0.69 \\
\tilde{\theta}_{r}^{f} & =\frac{1}{\frac{N_{s}^{f}}{\left(N_{r}^{f}\right)(1-\phi)}+1} \\
& =\frac{1}{\frac{15}{(28)(1-0.3)+1}} \\
& =0.57
\end{aligned}
$$

We can adjust the decomposition for sampling error by noting that

$$
\begin{gathered}
\theta_{r}^{m}=\tilde{\theta}_{r}^{m}+\tilde{\delta}_{r}^{m} \\
\theta_{r}^{f}=\tilde{\theta}_{r}^{f}+\tilde{\delta}_{r}^{f},
\end{gathered}
$$

where $\tilde{\delta}_{r}^{m}$ and $\tilde{\delta}_{r}^{f}$ are the deviations between realized and expected wage proportions for 
men and women:

$$
\begin{aligned}
\tilde{\delta}_{r}^{m} & =\theta_{r}^{m}-\tilde{\theta}_{r}^{m} \\
& =0.70-0.69 \\
& =0.01 \\
\tilde{\delta}_{r}^{f} & =\theta_{r}^{f}-\tilde{\theta}_{r}^{f} \\
& =0.54-0.57 \\
& =-0.03
\end{aligned}
$$

The job choice decomposition component when the male weights are used can be expressed as

$$
\left(\gamma_{r} P_{r}^{f}-\gamma_{s} P_{s}^{f}\right)\left(\theta_{r}^{m}-\theta_{r}^{f}\right)=\left(\gamma_{r} P_{r}^{f}-\gamma_{s} P_{s}^{f}\right)\left(\tilde{\theta}_{r}^{m}-\tilde{\theta}_{r}^{f}\right)+\left(\gamma_{r} P_{r}^{f}-\gamma_{s} P_{s}^{f}\right)\left(\tilde{\delta}_{r}^{m}-\tilde{\delta}_{r}^{f}\right)
$$

where $\left(\gamma_{r} P_{r}^{f}-\gamma_{s} P_{s}^{f}\right)\left(\tilde{\theta}_{r}^{m}-\tilde{\theta}_{r}^{f}\right)$ is the expected job choice wage gap and $\left(\gamma_{r} P_{r}^{f}-\gamma_{s} P_{s}^{f}\right)\left(\tilde{\delta}_{r}^{m}-\tilde{\delta}_{r}^{f}\right)$ is the job choice wage gap from sampling error.

The productivity decomposition components when the male weights are used can be expressed as

$$
\begin{aligned}
& \gamma_{r}\left(P_{r}^{m}-P_{r}^{f}\right) \theta_{r}^{m}+\gamma_{s}\left(P_{s}^{m}-P_{s}^{f}\right)\left(1-\theta_{r}^{m}\right)=\gamma_{r}\left(P_{r}^{m}-P_{r}^{f}\right) \tilde{\theta}_{r}^{m}+\gamma_{s}\left(P_{s}^{m}-P_{s}^{f}\right)\left(1-\tilde{\theta}_{r}^{m}\right) \\
& \quad+\left[\gamma_{r}\left(P_{r}^{m}-P_{r}^{f}\right)-\gamma_{s}\left(P_{s}^{m}-P_{s}^{f}\right)\right] \tilde{\delta}_{r}^{m}
\end{aligned}
$$

where $\gamma_{r}\left(P_{r}^{m}-P_{r}^{f}\right) \tilde{\theta}_{r}^{m}+\gamma_{s}\left(P_{s}^{m}-P_{s}^{f}\right)\left(1-\tilde{\theta}_{r}^{m}\right)$ is the expected productivity wage gap, and

$\left[\gamma_{r}\left(P_{r}^{m}-P_{r}^{f}\right)-\gamma_{s}\left(P_{s}^{m}-P_{s}^{f}\right)\right] \tilde{\delta}_{r}^{m}$ is the productivity wage gap from sampling error.

In the present case we have the following decomposition components corrected for 
sampling error:

$$
\begin{aligned}
\left(\gamma_{r} P_{r}^{f}-\gamma_{s} P_{s}^{f}\right)\left(\tilde{\theta}_{r}^{m}-\tilde{\theta}_{r}^{f}\right) & =0.15 \text { (job choice) } \\
\gamma_{r}\left(P_{r}^{m}-P_{r}^{f}\right) \tilde{\theta}_{r}^{m}+\gamma_{s}\left(P_{s}^{m}-P_{s}^{f}\right)\left(1-\tilde{\theta}_{r}^{m}\right) & =0.29 \text { (productivity) } \\
\left(\gamma_{r} P_{r}^{f}-\gamma_{s} P_{s}^{f}\right)\left(\tilde{\delta}_{r}^{m}-\tilde{\delta}_{r}^{f}\right) & =0.05 \text { (job choice sampling error) } \\
{\left[\gamma_{r}\left(P_{r}^{m}-P_{r}^{f}\right)-\gamma_{s}\left(P_{s}^{m}-P_{s}^{f}\right)\right] \tilde{\delta}_{r}^{m} } & =0.00 \text { (productivity sampling error) } \\
\left(w_{m}-w_{f}\right)-\left(\hat{w}_{m}-\hat{w}_{f}\right) & =0.01 \text { (rounding error) }
\end{aligned}
$$

These results show that the job choice component is reduced from 0.20 (40\%) to 0.15 $(30 \%)$, the productivity component and the rounding error are unchanged, and sampling error accounts for $0.05(10 \%)$ of the wage gap.

Alternatively, the job choice decomposition component when the female weights are used can be expressed as

$$
\left(\gamma_{r} P_{r}^{m}-\gamma_{s} P_{s}^{m}\right)\left(\theta_{r}^{m}-\theta_{r}^{f}\right)=\left(\gamma_{r} P_{r}^{m}-\gamma_{s} P_{s}^{m}\right)\left(\tilde{\theta}_{r}^{m}-\tilde{\theta}_{r}^{f}\right)+\left(\gamma_{r} P_{r}^{m}-\gamma_{s} P_{s}^{m}\right)\left(\tilde{\delta}_{r}^{m}-\tilde{\delta}_{r}^{f}\right)
$$

where $\left(\gamma_{r} P_{r}^{m}-\gamma_{s} P_{s}^{m}\right)\left(\tilde{\theta}_{r}^{m}-\tilde{\theta}_{r}^{f}\right)$ is the expected job choice wage gap and $\left(\gamma_{r} P_{r}^{m}-\gamma_{s} P_{s}^{m}\right)\left(\tilde{\delta}_{r}^{m}-\tilde{\delta}_{r}^{f}\right)$ is the job choice wage gap from sampling error.

The productivity decomposition components when the female weights are used can be expressed as

$$
\begin{aligned}
& \gamma_{r}\left(P_{r}^{m}-P_{r}^{f}\right) \theta_{r}^{f}+\gamma_{s}\left(P_{s}^{m}-P_{s}^{f}\right)\left(1-\theta_{r}^{f}\right)=\gamma_{r}\left(P_{r}^{m}-P_{r}^{f}\right) \tilde{\theta}_{r}^{f}+\gamma_{s}\left(P_{s}^{m}-P_{s}^{f}\right)\left(1-\tilde{\theta}_{r}^{f}\right) \\
& \quad+\left[\gamma_{r}\left(P_{r}^{m}-P_{r}^{f}\right)-\gamma_{s}\left(P_{s}^{m}-P_{s}^{f}\right)\right] \tilde{\delta}_{r}^{f},
\end{aligned}
$$

where $\gamma_{r}\left(P_{r}^{m}-P_{r}^{f}\right) \tilde{\theta}_{r}^{f}+\gamma_{s}\left(P_{s}^{m}-P_{s}^{f}\right)\left(1-\tilde{\theta}_{r}^{f}\right)$ is the expected productivity wage gap, and

$\left[\gamma_{r}\left(P_{r}^{m}-P_{r}^{f}\right)-\gamma_{s}\left(P_{s}^{m}-P_{s}^{f}\right)\right] \tilde{\delta}_{r}^{f}$ is the productivity wage gap from sampling error.

In the present case we have the following decomposition components corrected for 
sampling error:

$$
\begin{aligned}
\left(\gamma_{r} P_{r}^{m}-\gamma_{s} P_{s}^{m}\right)\left(\tilde{\theta}_{r}^{m}-\tilde{\theta}_{r}^{f}\right) & =0.19 \text { (job choice) } \\
\gamma_{r}\left(P_{r}^{m}-P_{r}^{f}\right) \tilde{\theta}_{r}^{f}+\gamma_{s}\left(P_{s}^{m}-P_{s}^{f}\right)\left(1-\tilde{\theta}_{r}^{f}\right) & =0.25 \text { (productivity) } \\
\left(\gamma_{r} P_{r}^{m}-\gamma_{s} P_{s}^{m}\right)\left(\tilde{\delta}_{r}^{m}-\tilde{\delta}_{r}^{f}\right) & =0.06 \text { (job choice sampling error) } \\
{\left[\gamma_{r}\left(P_{r}^{m}-P_{r}^{f}\right)-\gamma_{s}\left(P_{s}^{m}-P_{s}^{f}\right)\right] \tilde{\delta}_{r}^{f} } & =-0.01 \text { (productivity sampling error) } \\
\left(w_{m}-w_{f}\right)-\left(\hat{w}_{m}-\hat{w}_{f}\right) & =0.01 \text { (rounding error) }
\end{aligned}
$$

These results show that the job choice component is reduced from $0.26(52 \%)$ to $0.19(38 \%)$, the productivity component is increased from 0.24 (48\%) to 0.25 (50\%), the rounding error increases from $0.00(0 \%)$ to $0.01(2 \%)$, and sampling error accounts for $0.05(10 \%)$ of the wage gap.

\section{TA3. Constant Absolute Risk Aversion}

As part of our empirical analysis, we examine the extent to which subject job choices can be rationalized by a class of utility functions. We consider the class of utility functions corresponding to Constant Absolute Risk Aversion (CARA). In the interest of simplicity, we adapt the mean-variance portfolio Markowitz (1952) model as described in Wenner (2002) to binary selection between the secure job and the risky job. The random utilities of the job gambles are expressed as

$$
\begin{gathered}
U_{s i}=y_{s i}+\varepsilon_{s i}(\text { secure job }) \\
U_{r i}=y_{r i}-\frac{\alpha}{2} \sigma_{r i}^{2}+\varepsilon_{r i}(\text { risky job }),
\end{gathered}
$$

where $\alpha$ is the Pratt-Arrow measure of constant absolute risk aversion, and $\sigma_{r i}^{2}=(\phi)(1-\phi)\left(\gamma_{r} \psi_{i}-w_{u}\right)^{2}$ is the conditional (on $\left.\psi_{i}\right)$ variance of wages on the risky job.

Let $\sigma_{s r}^{2}=$ variance of $\varepsilon_{s i}-\varepsilon_{r i}$. The probability that one would select the risky job is 
given by

$$
\begin{aligned}
\operatorname{Prob}\left(J=r \mid \psi_{i}\right) & =\operatorname{Prob}\left(U_{r i}>U_{s i}\right) \\
& =\operatorname{Prob}\left(y_{r i}-\frac{\alpha}{2} \sigma_{r i}^{2}+\varepsilon_{r i}>y_{s i}+\varepsilon_{s i}\right) \\
& =\operatorname{Prob}\left(y_{r i}-y_{s i}-\frac{\alpha}{2} \sigma_{r i}^{2}>\varepsilon_{s i}-\varepsilon_{r i}\right) \\
& =\operatorname{Prob}\left(\frac{\varepsilon_{s i}-\varepsilon_{r i}}{\sigma_{s r}}<\frac{y_{r i}-y_{s i}}{\sigma_{s r}}-\frac{\alpha}{2 \sigma_{s r}} \sigma_{r i}^{2}\right) \\
& =\operatorname{Prob}\left(\frac{\varepsilon_{s i}-\varepsilon_{r i}}{\sigma_{s r}}<I_{i}\right) \\
& =\Phi\left(I_{i}\right),
\end{aligned}
$$

where $I_{i}=\lambda_{1}\left(y_{r i}-y_{s i}\right)+\lambda_{2}\left(\frac{-\sigma_{r i}^{2}}{2}\right), \lambda_{1}=\frac{1}{\sigma_{s r}}>0$, and $\lambda_{2}=\frac{\alpha}{\sigma_{s r}} \gtreqless 0$. It is readily apparent that the probit standard deviation is identified from $\sigma_{s r}=\frac{1}{\lambda_{1}}$, or the variance from $\sigma_{s r}^{2}=\frac{1}{\left(\lambda_{1}\right)^{2}}$. Defining the risky job variance variable as $\frac{-\sigma_{r i}^{2}}{2}$ allows us to directly estimate $\alpha$ as $\tilde{\alpha}=\frac{\tilde{\lambda}_{2}}{\tilde{\lambda}_{1}}$. Furthermore, with this model we can directly compare the $\tilde{\alpha}_{m}$ and $\tilde{\alpha_{f}}$ risk aversion parameter estimates for males and females.

In order to achieve a larger sample size, a single probit model is estimated from the pooled sample of men and women. A gender interaction term for the conditional variance on the risky job is added to the probit index function in order to identify gender differences in the effects of risky job income variance on job choice:

$$
I_{i}=\lambda_{1}\left(y_{r i}-y_{s i}\right)+\lambda_{2}\left(\frac{-\sigma_{r i}^{2}}{2}\right)+\lambda_{3}\left(\frac{-\sigma_{r i}^{2} F_{i}}{2}\right)
$$

where $F_{i}=1$ (female). Identification of the CARA risk aversion parameters for men and women comes from $\alpha_{m}=\frac{\lambda_{2}}{\lambda_{1}}$ and $\alpha_{f}=\frac{\lambda_{2}+\lambda_{3}}{\lambda_{1}}$.

Because an individual's conditional variance of wages on the risky job $\sigma_{r i}^{2}$ depends on their unobserved expected productivity $\psi_{i}$, it is necessary to estimate expected productivity for each subject. Our estimate $\hat{\psi}_{i}$ is calculated as the average of the subject's final 5 observed performances in their last assigned treatment. The presumption is that this estimate is a reasonable estimate of expected productivity and is a good measure of a 
subject's own beliefs about their productivity at the time they choose between the risky and the secure job.

TA Table 1: Gender Differences in the Pratt-Arrow

CARA Risk Preferences Parameters $(\alpha)$

(Mean-Variance Utility Function)

\begin{tabular}{lc}
\hline \hline \multicolumn{1}{c}{ Test } & p value \\
\hline$H_{0}: \alpha_{m}=0, H_{1}: \alpha_{m} \neq 0$ & 0.194 \\
$H_{0}: \alpha_{f}=0, H_{1}: \alpha_{f} \neq 0$ & 0.052 \\
$H_{0}: \alpha_{m} \leq 0, H_{1}: \alpha_{m}>0$ & 0.457 \\
$H_{0}: \alpha_{f} \leq 0, H_{1}: \alpha_{f}>0$ & 0.026 \\
$H_{0}: \alpha_{f}=\alpha_{m}, H_{1}: \alpha_{f} \neq \alpha_{m}$ & 0.152 \\
$H_{0}: \alpha_{f} \leq \alpha_{m}, H_{1}: \alpha_{f}>\alpha_{m}$ & 0.076 \\
\hline Men: $\tilde{\alpha}_{m}=0.008, \tilde{\sigma}_{\tilde{\alpha}_{m}}=0.070$ \\
Women: $\tilde{\alpha}_{f}=0.127, \tilde{\sigma}_{\tilde{\alpha}_{f}}=0.066$ \\
\hline \hline
\end{tabular}

TA Table 1 reports test results for gender differences in risk preferences based on the estimated Pratt-Arrow $\alpha$ parameters obtained from the CARA mean-variance utility function model. The estimated $\alpha$ 's are inferred from the model as nonlinear functions of the estimated probit parameters and the associated standard errors are obtained by the delta method. Based on two-tailed tests, we cannot reject risk neutrality for men nor can we reject the hypothesis of no gender difference in $\alpha$. However, one can reject the hypothesis that women are risk neutral. A series of one-tailed tests shed additional light on gender differences in job risk attitudes as viewed through the lens of the CARA mean-variance utility function model. The hypothesis of risk loving behavior corresponds to $H_{0}: \alpha \leq 0, H_{1}: \alpha>0$. We find that one cannot reject the hypothesis of risk loving behavior for men but can reject risk loving for women. The hypothesis that women are less risk averse than men corresponds to $H_{0}: \alpha_{f}-\alpha_{m} \leq 0, H_{1}: \alpha_{f}-\alpha_{m}>0$. We are able to reject the hypothesis that women are less risk averse than men (in favor of the hypothesis that women are more risk averse than men).

\section{TA4. HL Risk Aversion}

We gathered data on individual risk aversion by having participants play an incentivized lottery game which was designed by Holt and Laury (2002). Following Andersen et al. 
(2006), we employ a switching multiple price list design, which therefore, allows only monotonic risk preference. As presented in Figure 2, participants have ten choices between two options, A and B. Option A pays either $€ 2$ or $€ 1.6$, whereas Option B pays either $€ 3.85$ or $€ 0.10$. Except the first choice in which there is no uncertainty, Option B is riskier and features a higher variance in possible payments. As the decision number rises, the probability of receiving the higher amount (€2 for Option A and $€ 3.85$ for Option B) falls. In other words, the probability of receiving the lower amount increases. A rational participant would switch to Option A from Option B at a certain decision number where selecting Option A gives higher utility than Option B, and that number varies across individuals with heterogeneous individual risk aversion. For example, a rational risk-neutral agent would switch his preferred option from B to A between decision numbers 5 and 6 where expected values for Option A and Option B are identical. For the final payment, one row is randomly chosen, and the lottery is then played according to the choice made by the participant. In this paper, we use the number of participant's choices for Option A (safe options) as our measure of risk aversion, which increases as the participant becomes more risk averse. 


\section{Appendix}

\section{Experimental Instruction ${ }^{1}$}

\section{Slide 1.}

-Good morning. Thank you for participating in this experiment. Please read these instructions carefully and, should you have any questions, raise your hand and call the administrator. Communication between participants is forbidden. Please turn off cellular phones. A payment in cash will be provided at the end of the session.

\section{Slide 2. Main rule}

-You will be required to perform an effort task thought this experiment.

-Each period lasts for 90 seconds; the clock starts when you open the first active screen, and stops after 90 seconds. During a period, the remaining time is displayed in the bottom of the screen (in seconds).

-During each period, the computer displays a sequence of blocks of five letters. Your task is to accurately type the given blocks of five letters in 90 seconds. The words can be separated by comma or space (using a space-bar key). The order of words do not matter.

-There are 3 sessions, and in each session, there are 10 periods.

-At the end of each period, the computer will display the total number of correct answers that you have provided.

-Only one period in each session will be randomly selected for the final payment. Your payment in Euro $(€)$ will be delivered at the end of the experiment. The payment is con-

\footnotetext{
${ }^{1}$ Translated from French.
} 
nected to performance in the task, according to a rule known to everyone.

\section{Slide 3. Description of two different schemes}

In the first two sessions, you will experience two different types of jobs, then in the third session you will choose which type of job that you will work for.

Type A: Each word that you correctly type gives you 20 centimes. However, there is a possibility of $30 \%$ that you are neither able to work nor to do anything but to seat silent for each period, in which you will gain $€ 1$. At the beginning of each period, you will run a random draw which determines whether you can work or not for that period.

Type B: Each word that you correctly type gives you 20 centimes. In this Type B, you can continuously experience all 10 periods.

\section{Slide 4. Typing Task Example}

-Figure 1 presents the example of the typing task that you will perform.

-If you have any questions, please raise your hand and address it to the administrator.

-If you are sure you have understood the rules of the game, you can press the button below to launch the experiment.

-The experiment starts when all subjects have pressed the button.

\section{Slide 5. Session 1: Type A, assigned ${ }^{2}$}

In this session, you will perform the typing task. Each period lasts 90 seconds. Each block of five letters that you correctly type will pay you 20 centimes. However, there is a possibility of $30 \%$ that you are neither able to work nor to do anything but to stay silent for each period, in which you will gain $€ 1$. At the beginning of each period, you will run

\footnotetext{
${ }^{2}$ The order of Type A and Type B is randomly assigned to each individual.
} 
TA Figure 1: Slide 4. Typing Task Example

licnm, xbevy, cpfqv, iysyc, fmigm, akqoj, xbmbv, qkcjg, jlkzf, mmgri, trphv, uogvt, ehdzi, hvfnx, mafvb, dfsmh, djppo, onsqv, rnenk, tguou, izmjs, brazv, crhny, iwfge spvgt, jppug, ffufp, yrrgk, fghlf, obuzq, suyyp, ihkrh, odgci, vmeca, tyjrg, vgorn, ezclx, hozow, qmthd, ypumf, wqbfw, ewqmx, kkobv, mfcga, Indkt, asukp, bbrzj, meolx, pwthz, ppqhu, wtcsl, oauia, vnvcu, fzpku, dssuu, qtgic, wutjx, yhvam, dmvub, tlyfo, mtfus, mnlfg, cwcsm, bdggq, evsmo, rrgaw, rdppn, aygvr, sazld, mfcxq, oayvn, tcayb, ymqhg, bieot, qgnvn, bunsb, afkrb, euzqm, ufzjv, szgke, byojw, wfldg, hkgpk, oatxa, rryfa, fqbcp, auxsu, eryxc, acphv, oexfr, hqekx, zfudp, cvgms, ktpnf, lyuxo, gudsl, cttiy, qxnaf, wclnv, pulgz

Veuillez recopier le mots ci-dessus

Il vous reste 83 seconde(s)

a random draw which determines whether you can work or not for that period. Press the start button when you are ready.

Slide 6. Random Draw: $30 \%$ possibility of being unemployed ${ }^{3}$

Push the random draw button.

Case1[Unemployed]- In this period, you are not able to perform the typing task. You will be seated silent for 90 seconds, and $€ 1$ will be paid.

Case2[Employed]- In this period, you are able to perform the typing task. Each block of five letters that you correctly type will pay you 20 centimes.

\section{Slide 7. Type A Typing Task Period}

\footnotetext{
${ }^{3}$ Slides 6,7 , and 8 are repeated for ten periods
} 
Case1[Unemployed]- Blank Screen with the clock in the bottom of the page

Case2[Employed]- Similar to "Example" in Slide 4

Slide 8. Results on this period

-Number of correctly typed blocks [ ]

-Payment if this period is selected for payment $€[]$

\section{Slide 9. Results on this session}

-Period selected for payment [ ]

-Number of correctly typed blocks in this selected period [ ]

-Payment for this session $€[]$

\section{Slide 10. Session 2: Type B, assigned ${ }^{4}$}

In this session, you will perform the typing task for all 10 periods. Each period lasts 90 seconds. Each block of five letters that you correctly type will pay you 13 centimes. ${ }^{5}$

Press the start button when you are ready.

\section{Slide 11. Type B Typing Task Period ${ }^{6}$}

Similar to "Example" in Slide 4

\section{Slide 12. Results on this period}

\footnotetext{
${ }^{4}$ Type A if the subject starts with Session B in Slide 5.

${ }^{5} 14$ centimes in $\mathrm{RP}=0.06$ treatment.

${ }^{6}$ Slides 11 and 12 are repeated for ten periods
} 
-Number of correctly typed blocks [ ]

-Payment if this period is selected for payment $€[]$

\section{Slide 13. Results on this session}

-Period selected for payment [ ]

-Number of correctly typed blocks in this selected period [ ]

-Payment for this session $€[]$

\section{Slide 14. Session 3: Job Choice}

You have experienced two different types of jobs in Session 1 and Session 2. In this session, you will choose which type of job that you will perform. Here are the description of each type.

Type A: Each word that you correctly type gives you 20 centimes. However, there is a possibility of $30 \%$ that you are neither able to work nor to do anything but to stay silent for each period, in which you will gain $€ 1$. At the beginning of each period, you will run a random draw which determines whether you can work or not for that period.

Type B: Each word that you correctly type gives you 20 centimes. In this Type B, you can continuously experience all 10 periods.

-Choose one type between Type A and Type B: [A/B]

-Press start button when you are ready to perform the last session.

\section{Slide 15. Session 3: Typing Task Period}

Repeat Slides 6-9 or Slides 11-13 depending on which type the subject chooses. 


\section{Slide 16. Questionnaires}

You have all finished the main sessions. Now we will collect some of your information. Please answer to the following questions.

-You are: [A man / A woman]

-Your age is $[\mathrm{X}]$

\section{Slide 17. Holt and Laury Risk Question}

In this task, you have a chance to earn extra payment upon your choice. Figure 2 on the next screen shows ten decisions. Each decision is a paired choice between "Option A" and "Option B". You will make ten choices by clicking one of circles which corresponds to each options, in the middle of the two options. Only one of them will be randomly selected for payment. Please raise you hand if you have any question. Push the start button if you are ready.

\section{Slide 18. Holt and Laury Risk Question}

Figure 2 is displayed on the screen.

Press OK to continue.

\section{Slide 19. Holt and Laury Risk Question Result}

-Selected decision number []

-Your choice [Option A/Option B]

-Realised Value for your choice $€[]$ 
TA Figure2: HL Risk Questions

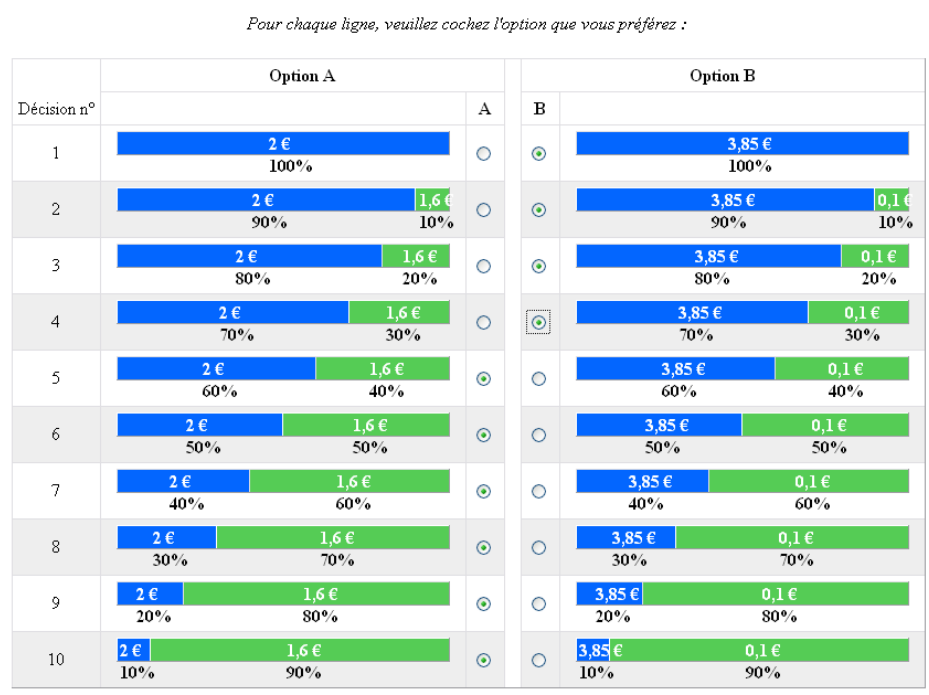

Appuyez sur OK pour continuer :

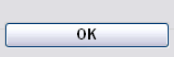

\section{Slide 20. End of Experiment}

-Payment in Session $1 €[]$

-Payment in Session $2 €[]$

-Payment in Session $3 €[$ ]

-Payment in HL Questions []

-Show up Fee $€[]$

-Thank you for having participated in this experiment. The total gain for the experiment is $€[]$.

\section{References}

Andersen, S., G. W. Harrison, M. I. Lau, and E. E. Rutstrom (2006). Elicitation using multiple price list formats. Experimental Economics 9(4), 383-405.

Holt, C. A. and S. K. Laury (2002). Risk aversion and incentive effects. American Economic 
Review 92(5), 1644-1655.

Markowitz, H. (1952). Portfolio selection. The Journal of Finance 7(1), 77-91.

Wenner, F. (2002). Determination of Risk Aversion and Moment-Preferences: A Comparison of Econometric Models. Doctoral dissertation, University of St. Gallen. 